\title{
The Feasibility of Integrating the Noble Scallop Mimachlamys nobilis with Existing Fish Monoculture Farms in the South China Sea: A Bioeconomic Assessment from Hong Kong
}

Author(s): Reece Wartenberg, Khem Limbu, Limin Feng, Jia Jun Wu, Leo L. Chan, Trevor C. Telfer and Paul K. S. Lam

Source: Journal of Shellfish Research, 37(3):635-650.

Published By: National Shellfisheries Association

https://doi.org/10.2983/035.037.0316

URL: http://www.bioone.org/doi/full/10.2983/035.037.0316

BioOne (www.bioone.org) is a nonprofit, online aggregation of core research in the biological, ecological, and environmental sciences. BioOne provides a sustainable online platform for over 170 journals and books published by nonprofit societies, associations, museums, institutions, and presses.

Your use of this PDF, the BioOne Web site, and all posted and associated content indicates your acceptance of BioOne's Terms of Use, available at www.bioone.org/page/terms of use.

Usage of BioOne content is strictly limited to personal, educational, and non-commercial use. Commercial inquiries or rights and permissions requests should be directed to the individual publisher as copyright holder. 


\title{
THE FEASIBILITY OF INTEGRATING THE NOBLE SCALLOP MIMACHLAMYS NOBILIS WITH EXISTING FISH MONOCULTURE FARMS IN THE SOUTH CHINA SEA: A BIOECONOMIC ASSESSMENT FROM HONG KONG
}

\author{
REECE WARTENBERG, ${ }^{1,2,3 *}$ KHEM LIMBU, ${ }^{1,2}$ LIMIN FENG,${ }^{1,3}$ JIA JUN WU, ${ }^{1,3}$ \\ LEO L. CHAN, ${ }^{1,3,4}$ TREVOR C. TELFER ${ }^{5}$ AND PAUL K. S. LAM ${ }^{1,2,3}$ \\ ${ }^{1}$ State Key Laboratory in Marine Pollution, City University of Hong Kong, Tat Chee Avenue, Kowloon, \\ Hong Kong SAR, China; ${ }^{2}$ Department of Chemistry, City University of Hong Kong, Tat Chee Avenue, \\ Hong Kong SAR, China, ${ }^{3}$ Research Centre for the Oceans and Human Health, Shenzhen Key Laboratory \\ for Sustainable Use of Marine Biodiversity, City University of Hong Kong Shenzhen, Research Institute \\ Building, Shenzhen, Guangdong 518057, China; ${ }^{4}$ Department of Biomedical Sciences, City University of \\ Hong Kong, Tat Chee Avenue, Hong Kong SAR, China; ${ }^{5}$ Institute of Aquaculture, University of Stirling, \\ Grange Road, Stirling FK9 4LA, United Kingdom
}

\begin{abstract}
The environmental implications of integrated multitrophic aquaculture have been well studied in China, but few investigations have empirically explored potential economic benefits. This study investigated the technical and economic feasibility of physically integrating the noble scallop Mimachlamys nobilis (Reeve, 1852) with existing fish monoculture farms in Hong Kong. Scallops were grown for 201 days from June to December in lantern nets hung directly from fish farm platforms at treatment depths of 1,3.5, and $6 \mathrm{~m}$. Only the $1-\mathrm{m}$ treatment attained the target mean height-at-harvest of $80 \mathrm{~mm}$. Fitted von Bertalanffy growth functions showed significant differences in growth performance between depths. The von Bertalanffy growth function projected that the 3.5- and 6-m treatments would require an additional 26 and 59 days of culture to reach $80 \mathrm{~mm}$. Mortality was significantly lower at $1 \mathrm{~m}(53 \% \pm 12.5 \%)$ compared with those at $3.5 \mathrm{~m}(70 \% \pm 9.0 \%)$ and $6 \mathrm{~m}(83 \% \pm 4.5 \%)$. The slower growth and higher mortality at 3.5 and $6 \mathrm{~m}$ were probably due to periodically low oxygen which dropped to $4.96,3.08$, and $1.73 \mathrm{mg} \mathrm{L}^{-1}$ at 1, 3.5, and $6 \mathrm{~m}$, respectively, in midsummer. A bioeconomic assessments of two typical farm sizes was conducted; small $\left(45 \mathrm{~m}^{2}\right)$ and large $\left(315 \mathrm{~m}^{2}\right)$. The initial investment, discounted payback time, and 10-y net present value of the projects was US\$5,485.51, $3 \mathrm{y}$, and US\$20,211.33, respectively, for the small farm and US\$27,659.03, $2 \mathrm{y}$, and US\$227,406.49, respectively, for the large farm. Sensitivity analysis revealed that the profitability of operations was sensitive to changes in mortality and sales price. This study has confirmed that physically integrating M. nobilis at existing fish farms is technically and economically feasible.
\end{abstract}

KEY WORDS: scallop, Mimachlamys nobilis, bioeconomic, economic, integrated multi-trophic aquaculture, feasibility

\section{INTRODUCTION}

Cage and longline aquaculture in the open sea, collectively called suspended aquaculture, has been expanding to help meet the growing global demand for seafood. A limitation to the suspended aquaculture of fed species such as finfish is that cage systems are essentially open and so intensive production can pollute the supporting water body (Cao et al. 2007, Chen et al. 2007). In China, at least 18 adverse impacts including chemical, ecological, physical, and socioeconomic impacts have been shown to originate from suspended aquaculture (Wartenberg et al. 2017). If the environmental, economic, and social sustainability of suspended aquaculture is to be insured over the long term, then farming systems that minimize negative impacts and improve consumer perceptions are needed (Ridler et al. 2007).

One frequent recommendation for improving suspended aquaculture is integrated multitrophic aquaculture (IMTA). Prototypical IMTA integrates low-trophic-level, extractive species with fed finfish such that the extractive species can assimilate waste and produce additional, commercially valuable secondary products (Chopin et al. 1999, Neori et al. 2004, Barrington et al. 2009). Research on IMTA has shown that macroalgae, shellfish, and echinoderms can process dissolved nutrients, suspended particulates, and settling particulates at cage farming areas, thereby remediating some of the waste

*Corresponding author. E-mail: reece.wartenberg@gmail.com DOI: $10.2983 / 035.037 .0316$ released from fish farms (Nobre et al. 2010, Shi et al. 2013 , Chopin 2015).

In China, research on IMTA in suspended aquaculture systems has been going on since the mid1990s, but important knowledge gaps remain (Fang et al. 1996, Qian et al. 1996, Nunes et al. 2003, Ferreira et al. 2009). Research has been heavily focused in northern China and few studies have quantified the economic implications of IMTA (Shi et al. 2013, Wartenberg et al. 2017). Because of the wide longitudinal expanse of China $\left(17-40^{\circ} \mathrm{N}\right)$, research on IMTA candidate species from all regions is necessary to identify production opportunities and bottlenecks, and to facilitate the commercial adoption of engineered systems. In southern China, there is only limited information on IMTA and the question of economic viability has not been addressed (e.g., Yu et al. 2013, 2014a, 2014b, 2016). Quantitative information on the economics of IMTA is essential for industry adoption because unless farmers can see a direct financial benefit, it is unlikely that IMTA would be implemented commercially.

One promising candidate species for use in engineered IMTA systems in the South China Sea is the noble scallop, or huagui scallop, Mimachlamys nobilis (Reeve, 1852). The noble scallop is the primary commercial scallop species from southern China and is commonly sold at shell heights ( $\mathrm{SH})$ of $65-80 \mathrm{~mm}$ (Guo \& Luo 2016). The natural distribution of M. nobilis is from 19 to $22^{\circ} \mathrm{N}$. The species grows faster, and to a larger size, than the zhikong scallop, Chlamys farreri (Müller, 1776) which 
is farmed in northern China and accounts for $60 \%$ of scallop production in the country (Guo \& Luo 2016). There are hatcheries in Guangdong and Fujian that produce M. nobilis spat, and so there is an established supply of seed. Despite the suitability of $M$. nobilis for inclusion in IMTA systems in southern China, no previous study has attempted to directly integrate this scallop at existing fish farms.

Hong Kong SAR is a region in the South China Sea that has designated aquaculture zones exclusively occupied by fish monoculture operations. Fish are farmed in square net cages, typically $4 \times 4 \times 4 \mathrm{~m}$, suspended under floating platforms. Net cages are usually accompanied by open deck areas that provide space for husbandry activity. These collective floating structures are known as fish rafts. This style of aquaculture is used widely throughout Asia, and so research findings from IMTA in Hong Kong could be applied to the rest of the South China Sea with minimal modifications. Hong Kong is situated directly adjacent to Daya Bay which, in the past, was reported to have a naturally high abundance of Mimachlamys nobilis but the species has been commercially exploited in recent years (Guo \& Luo 2016, Lü et al. 2017). Preliminary work on IMTA in Hong Kong used the mussel Perna viridis (Linnaeus, 1758), stable isotope analysis and fatty acid profiling to show that $P$. viridis could assimilate fish farm waste when cultivated adjacent to fish cages (Gao et al. 2006). Despite exhibiting good growth rates in field trials $P$. viridis remains commercially unutilised in Hong Kong because it has a low market value (Wong \& Cheung 2001). The commercially valuable $M$. nobilis is, therefore, a promising candidate species for use in IMTA systems in the region.

The aim of this study was to determine if the physical integration of Mimachlamys nobilis at existing fish monoculture rafts is technically and economically feasible. Technical feasibility was assessed by growing $M$. nobilis at a commercial fish farm in Hong Kong using lantern nets suspended from the original raft structure. The field trial was carried out over 7 mo to establish baseline biological, technological, and economic factors associated with growing $M$. nobilis to produce a live product for distribution to local wholesale markets. Economic feasibility was assessed by coupling growth and mortality functions with empirical economic data to produce a comprehensive bioeconomic assessment of a potential scallop enterprise. To forecast the long-term viability of the operations, the bioeconomic assessment was simulated for two typical farm sizes over a 10 -y period.

\section{MATERIALS AND METHODS}

Site

Scallops were cultivated at Kau Sai fish culture zone (FCZ), one of 29 areas designated for suspended aquaculture in Hong Kong. Kau Sai FCZ $\left(22^{\circ} 21^{\prime} \mathrm{N}, 114^{\circ} 19^{\prime}\right.$ E) lies in a small, semienclosed bay within Port Shelter in the eastern waters of Hong Kong (Fig. 1). The FCZ has a total area of 46,200 $\mathrm{m}^{2}$ and, at the time of the experiment, $13,057 \mathrm{~m}^{2}$ was licensed for fish rafts. The fish stock in the culture zone is maintained up to $500 \mathrm{t}$ and stocked at an average density of $4.5 \mathrm{~kg} \mathrm{~m}^{-3}$. The maximum depth under the fish raft used for the scallop field trial was $14 \mathrm{~m}$ at high tide. Typical tidal amplitudes in the area are 1-2 $\mathrm{m}$. The water temperature in Port Shelter can range from $15^{\circ} \mathrm{C}$ in winter to $29^{\circ} \mathrm{C}$ in summer whereas salinity is normally between 28 and 34 depending on rainfall (EPD 2016).

\section{Scallop Stock}

Scallops $(n=723, \mathrm{SH}=44 \pm 5 \mathrm{~mm})$ were dry-transported in polystyrene boxes at a temperature of approximately $20^{\circ} \mathrm{C}$ from a lantern-net system in Fujian, Peoples Republic of China. Total transport time from packing to stocking at the study site was approximately $8 \mathrm{~h}$. On arrival at the farm each box of scallops, containing 350 individuals, was allocated to an aerated $100 \mathrm{~L}$ tank for acclimation. Wild Mimachlamys nobilis occupy habitats with water temperatures ranging from $8^{\circ} \mathrm{C}$ to $32^{\circ} \mathrm{C}$, with $20^{\circ} \mathrm{C}-25^{\circ} \mathrm{C}$ considered optimal (Guo \& Luo 2016). Although the optimal rate of temperature acclimation has not been determined for $M$. nobilis, relatively large scallops are generally resilient to changes in temperatures within their optimal range (Shumway \& Parsons 2016). The water temperature of the tanks was, therefore, increased at a rate of $4^{\circ} \mathrm{C} / \mathrm{h}$ by adding ambient seawater until it matched the temperature of the seawater of the fish farm at $24^{\circ} \mathrm{C}$. After temperature acclimation, scallops were then placed in lantern nets that were suspended directly from the platforms of the fish raft for a 2-wk environmental acclimation period. The stocking density of each net layer was $45 \%$ surface area coverage during acclimation. Mortality that may have been caused by transport and the acclimation process was taken as the number of dead scallops at the end of the 2-wk acclimation period (Sarkis et al. 2005).

\section{Experimental Design}

Scallops were grown in 14-layer, 2-cm monofilament, 50-cm diameter lantern nets in the central part of a fish monoculture farm that had 94 fish cages that were $4 \times 4 \times 4$ m each. Lantern nets were hung directly from the existing raft platforms in the space between fish cages such that normal fish husbandry activities were unaffected by the addition of scallops. Total fish stock was maintained up to $27 \mathrm{t}$ depending on normal husbandry activities. The pompano Trachinotus blochii (Lacépède, 1801) was cultured in all cages directly adjacent to the scallops whereas various Serranidae and Lutjanidae were cultured in other areas of the raft.

Scallops were farmed for a period of 201 days from May 29 to December 16, 2016, through the peak of summer when water temperatures are warmest because this has been identified as the optimal period for Mimachlamys nobilis growth (Guo \& Luo 2016). Each lantern net layer was considered one replicate and scallops were stocked at a density of $45 \%$ surface area coverage (42 scallops/layer). Scallop farmers in Southern China will typically stock scallops covering an area of $60 \%-80 \%$ (Guo \& Luo 2006). A stocking density of $45 \%$ was used as a precautionary measure against the possibility of reduced growth at higher stocking densities during this baseline study. To avoid complications associated with acute lantern net biofouling, such as the inhibition of food supply to scallops, fouled nets were replaced with clean nets during monthly sampling events. Regular net replacement is a common measure used to reduce biofouling in suspended scallop aquaculture (Qi et al. 2014).

The lantern net method allows farmers to grow scallops across the full depth range of the water column. In the protected bays of Hong Kong, however, strong water column stratification is common during the summer monsoon season and areas close to the sea floor can be anoxic year-round because of sludge build up (Yin 2002, Zhou et al. 2012). To test for potential differences in scallop production at different depths, three depth 


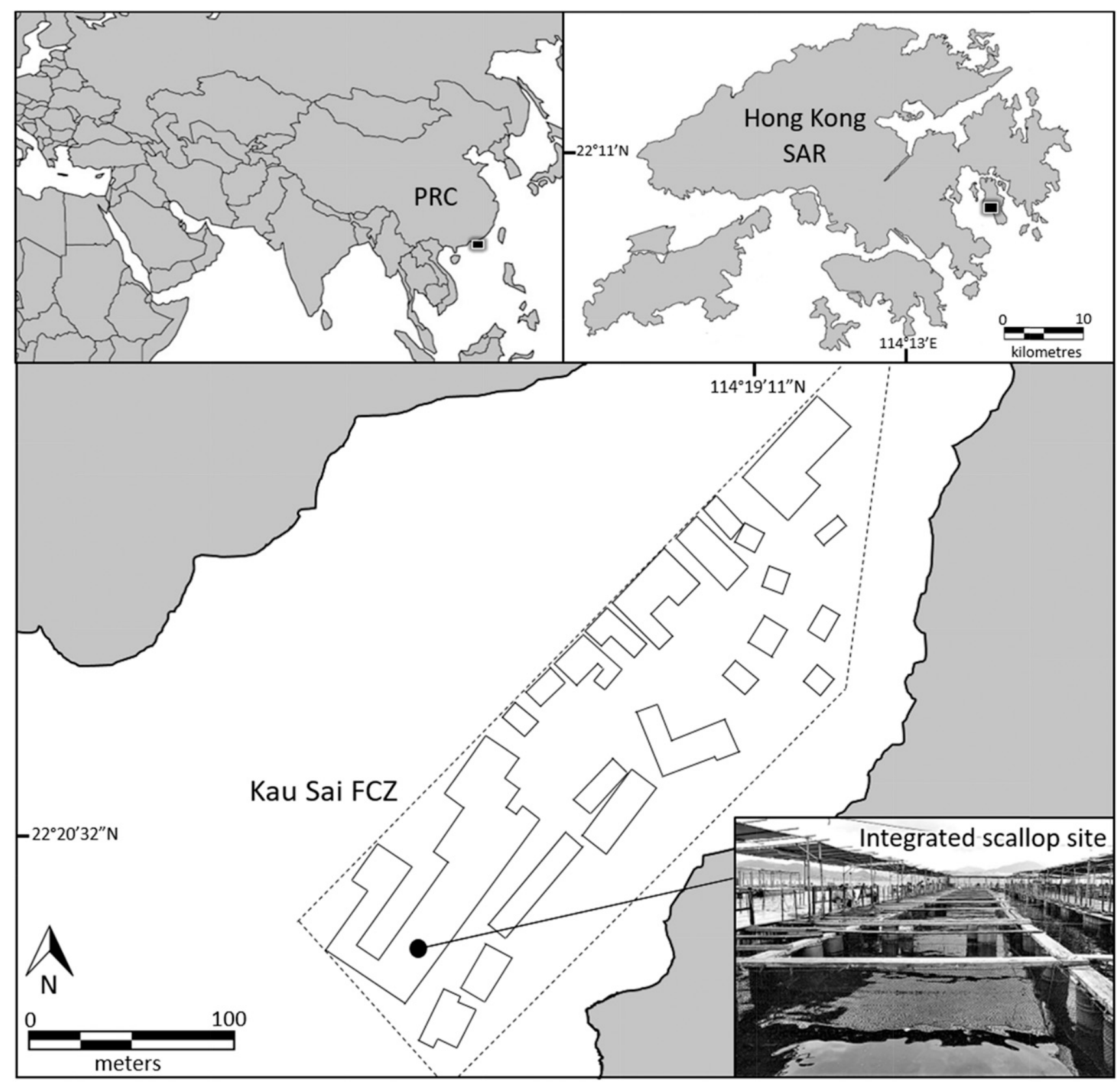

Figure 1. Map of the Kau Sai FCZ in Hong Kong SAR indicating the site used for the integrated scallop grow-out experiment. PRC, People's Republic of China.

treatments were selected; $1 \mathrm{~m}(n=6), 3.5 \mathrm{~m}(n=3)$, and $6 \mathrm{~m}(n=6)$. To afford greater experimental control and to prevent pseudoreplication between and within treatments, lantern net layers above and below the depth classes were left empty. The shallowest treatment was set at $1 \mathrm{~m}$ because it was anticipated that this would be shallow enough to test for potential exposure to low salinities from monsoon rain - it is a common perception among local farmers that animals cultivated near the surface are susceptible to high mortality from monsoon rain, but no previous study has confirmed this hypothesis. The deepest treatment was set at $6 \mathrm{~m}$ because it was expected that this would be shallow enough to avoid complications associated with periodic hypoxic conditions in the lower few meters of the water column (Yin 2002), and would be deep enough to provide biological data on the potential 3-dimensional use of the upper $6 \mathrm{~m}$ of the water column.

\section{Environmental Parameters}

Environmental parameters were measured on 26 occasions over the study period, at least biweekly. Temperature, oxygen, salinity, and total chlorophyll were measured using a YSI sonde EXOII (ㄷ Xylem) which was deployed at three predetermined, discrete locations adjacent to the scallop lantern nets at approximately midday. The sonde was deployed to a maximum depth of $12 \mathrm{~m}$ to avoid contacting the sea floor which had 
a maximum depth of $14 \mathrm{~m}$ at full high tide. Suspended particulate matter (SPM) concentrations were determined using a water sampler to collect triplicate $1 \mathrm{~L}$ water samples from treatment depths. Water was filtered using preweighed and preashed glass fiber filter papers (GC-50, (C) Advantec) before transport back to the laboratory for filter freeze drying and weighing.

\section{Growth and Mortality}

Scallop SH, and the number of dead scallops, was assessed monthly. Shell height was measured to the nearest mm using Vernier callipers. Dead scallops included gapers (newly deceased with soft tissues present), boxes (shells without soft tissue), and disarticulated shells (separated valves) that were removed from lantern nets monthly (Xiao et al. 2005). Growth was modeled by fitting a von Bertalanffy growth function (VBGF) to height-at-time data for the culture period. Some previous studies have used variations of the original VBGF, referred to as the specialized VBGF, to model scallop growth (Taylor et al. 2006, Mendo et al. 2011). To avoid statistical overfitting, the original form of the VBGF was used in the present study. The VBGF was expressed as $H_{t}=H_{\infty}\left(1-\exp \left[-K\left(t-t_{0}\right)\right]\right)$, where $H_{t}$ is the height at age in $\mathrm{mm}, H_{\infty}$ is the predicted asymptotic height, $K$ is a growth coefficient representing the rate at which individuals approach $H_{\infty}$, and $t_{0}$ is the age at zero length. Curves were fitted by minimizing a negated normal log-likelihood function. A likelihood ratio test was used to test the null hypothesis that there were no differences in VBGF parameters between treatments. Parameter variability was calculated using a parametric bootstrapping procedure with 1,000 iterations to determine SE (Efron 1982, Buckland 1984). As scallops were harvested before reaching their maximum reported height of $120 \mathrm{~mm}$ (Guo \& Luo 2016), the VBGF was first fitted by optimizing all parameters to compare $H_{\infty}$ between treatments, and then by fixing $H_{\infty}$ at $120 \mathrm{~mm}$ to compare growth coefficients $(K)$ between treatments. To facilitate between-study comparisons of growth, specific growth rate $\left(\% \mathrm{day}^{-1}\right)$ was calculated as $\mathrm{SGR}=\left[\left(\ln H_{2}-\ln H_{1}\right) / t\right] \times 100$, where $H_{1}$ and $H_{2}$ are the initial and final SH and $t$ is the interval (in days) between $H_{1}$ and $H_{2}$. Mortality data were used to estimate instantaneous total mortality $(Z)$ as the inverse-variance weighted average of a catch-curve analysis (Ricker 1975). To test for differences in mortality between treatments, Kaplan-Meier survival curves (Kaplan \& Meier 1958) were compared using log-rank tests (Mantel 1966, Mendo et al. 2011).

\section{Shell Biofouling Index}

Although lantern net biofouling was minimized by replacing nets monthly, the fouling on scallop shells was not removed unless it impeded measurements of SH. Previous work, reviewed by Adams et al. (2011), has shown that shell biofouling can significantly reduce growth and increase mortality to levels that can undermine farm viability. To test if high biofouling may explain the high mortality observed in July and August of the present study, the shells of 30 deceased scallops from each treatment were transported back to the laboratory after the August sampling. Fouled shells were dried at $60^{\circ} \mathrm{C}$ to constant weight and weighed. Biofouling was removed with a scraper before cleaned shells were weighed. Biofouling dry weight was calculated as shell weight loss after biofouling removal. The biofouling index was calculated by dividing the dry weight of the biofouling by the dry weight of the fouled shell and multiplying by 100 .

\section{Condition Indices}

In China, high quality live scallops have a large adductor muscle and full gonad. For the assessment of the condition of these soft tissues additional scallops were held in additional lantern nets suspended at $3.5 \mathrm{~m}$ for periodic harvesting. Soft tissue condition was assessed at the start $(29 / 05, n=18)$, middle $(03 / 09, n=38)$, and end $(16 / 12, n=35)$ of the culture period. Adductor muscle, gonadosomatic and "remaining tissue" indices were calculated by dividing the weight of the relevant tissue by the total weight of soft tissue and multiplying by 100 (González et al. 2002, Taylor et al. 2006). To test for differences in biofouling and tissue indices between treatments, data homoscedasticity was tested using Levene's test and the normality of treatment residuals was tested using Shapiro-Wilk's test. Analysis of variances were then used to test the null hypothesis that the treatment means were equal.

\section{Economic Feasibility}

A precautionary approach was used when compiling the business model used in the economic feasibility assessment because an integrated scallop-fish farm would be the first of its kind in Hong Kong. The assessment assumed that all lantern nets would be suspended at a depth of $1 \mathrm{~m}$ because of the favorable growth and mortality demonstrated by scallops from that treatment. The production system was based on a single annual stocking of Mimachlamys nobilis at the beginning June for their final stage of grow-out from $45 \mathrm{~mm} \mathrm{SH}$. Complete stock harvest occurred in December when the scallops reached $80 \mathrm{~mm}$ mean $\mathrm{SH}$. This simple system was selected because it does not require substantial additions of equipment or labor and would be straightforward for farmers to implement as an initial scallop enterprise. The estimated capital and operating expenses that would be incurred were used to determine the net returns from the scallop enterprise simulated over $10 \mathrm{y}$. Monetary values in the assessment were as of September 2017 and have been converted from Hong Kong dollars to U.S. dollars at a rate of HK\$7.80:US\$1.00 to facilitate international comparisons. Simulations were run assuming an annual interest rate of 5\% (retrieved July 20, 2017 from HSBC Hong Kong), an annual inflation rate of $3.58 \%$ (average annual inflation in Hong Kong from 2006 to 2016), and a profit tax of 15\% (as for unincorporated businesses in the region). Two representative raft sizes were evaluated; small $\left(45 \mathrm{~m}^{2}\right.$, nine fish cages, $2.6 \mathrm{t}$ fish standing stock, 48 active lantern nets, and two existing staff) and large ( $315 \mathrm{~m}^{2}, 70$ fish cages, $20.2 \mathrm{t}$ fish standing stock, 340 active lantern nets, and six existing staff), based on mean raft sizes for small and large rafts in FCZ in Hong Kong.

\section{Expenses}

It was assumed that all fixed capital and operating expenses were carried by the existing fish monoculture operation. These included the raft structure, moorings, vessels, existing permanent staff, and licenses. Costs associated with the scallop operation were, therefore, allocated to variable capital expenses, 
variable operating expenses, and the financing costs associated with a 5-y bank loan to fund the initial expenses required to establish a scallop enterprise. Precise costing was obtained using the actual expenses from the grow-out trial. In cases where additional capital equipment would be necessary for larger systems, costs were based on actual quotations from suppliers. For example, the cost of supplementary flotation (200 L HDPE barrels) required to support the additional weight of full and fouled lantern nets was calculated and included in the assessment. The costs associated with additional labor was allocated to four tasks; scallop stocking on arrival, bimonthly lantern net replacement to limit net fouling, bimonthly lantern net cleaning to remove net fouling, and final harvest and shell cleaning before distribution. The additional labor that would be necessary for a full-scale scallop operation was calculated based on the time taken to complete these tasks during the field trial and was costed based on the hiring of part-time staff as needed. Animal health and food safety testing were not included because routine monitoring is coordinated by the Agriculture, Fisheries and Conservation Department of Hong Kong.

\section{Revenue}

Revenue estimates were made using pricing data from the Hong Kong Fish Market Organisation (retrieved on May 22 and July 21, 2017). The standard mass metric used in markets in China is the catty, but the specific mass of one catty can vary by region. In Hong Kong, one catty is equivalent to $606 \mathrm{~g}$ (approximately six $80-\mathrm{mm}$ scallops). The mean wholesale market price for scallops over the period was US\$5.76 (HK $\$ 45.00)$ per catty. A wholesale mark-up of $30 \%$, typical in local seafood markets, was used to determine the price received by farmers and was US\$4.03 (HK\$31.50). Annual net revenue was determined by subtracting total costs from gross revenue.

\section{Bioeconomic Assessment}

The bioeconomic assessment was compiled using parameters from the VBGF, the mortality $(Z)$ function, total expenses, and net revenue to evaluate the profitability of the scallop enterprise (Taylor et al. 2006, Mendo et al. 2011). The number of lantern nets that could be integrated at a raft was calculated by evaluating the number of fish cage sides available for lantern net hanging at a density of 1 lantern net $/ \mathrm{m}$. Key parameters used in the assessment are given in Table 1. The initial scallop stocking density per layer $\left(\mathrm{SD}_{\text {initial }}\right)$ was calculated as $\mathrm{SD}_{\text {initial }}=\mathrm{SD}_{\text {harvest }} /(1-Z)$, where $\mathrm{SD}_{\text {harvest }}$ is the target stocking density at harvest and $Z$ is the anticipated mortality based on data from the field trial (Table 1). The standard economic valuation metrics net present value (NPV), internal rate of return (IRR), and the discounted payback time (DPBT) were used to assess the profitability of the initial investment over a 10-y operation (Penney \& Mills 2000). The NPV was calculated as NVP $=\sum_{t=0}^{n} \frac{C_{t}}{(1+r)^{t}}$, where $C_{t}$ represents the discounted annual cash flows, $t$ is the time of the cash flow, $n$ corresponds to the lifetime of the investment, and $r$ is the discount rate. The IRR was calculated by solving the NPV equation for $r$ when the NPV $=0$. The DPBT was calculated by adding the net revenues year-by-year to determine the year in which the total surpassed the initial investment. The DPBT was restricted to whole numbers, rounded up, because the business model was structured around a single annual harvest at the end of the year. A sensitivity analysis was used to simulate the effect of a $\pm 30 \%$ change in lantern net prices, seed stock price, transport mortality, growth $(K)$, grow-out mortality $(Z)$, minimum wage, and wholesale market price on the NPV of the investment. In running the assessment, it was assumed that the demand for live scallops was higher than supply, which is reasonable considering that this operation would be the first of its kind in Hong Kong and all scallops currently sold locally are imported.

\section{RESULTS}

\section{Environmental Parameters}

The water column at Kau Sai FCZ exhibited clear temperature, oxygen and salinity stratification from the start of the culture period in June until mid-September (Fig. 2). From mid-September to the end of the culture period in December these parameters were homogenous across depth classes. The warmest daytime water temperature was $29.13^{\circ} \mathrm{C}$ and was observed at $1 \mathrm{~m}$ in August. All treatments dropped to a low of $21.28^{\circ} \mathrm{C}$ in December. The lowest salinity of 30.61 was observed at $1 \mathrm{~m}$ on July 15 following heavy monsoon rain which was the same day that the minimum oxygen concentration of $1.73 \mathrm{mg} \mathrm{L}^{-1}$ was observed at $6 \mathrm{~m}$. There was no correlation between chlorophyll and SPM concentrations at $1 \mathrm{~m}(r=-0.13), 3.5 \mathrm{~m}(r=0.31)$, and $6 \mathrm{~m}(r=0.05)$.

\section{Growth and Mortality}

When VBGF were fitted to the data by optimizing $H_{\infty}, K$, and $t_{0}$, the growth curves were significantly different between the 1 - and 6-m treatments $\left(X^{2}=17.460,3\right.$ d.f., $\left.P=0.001\right)$, but the $3.5-\mathrm{m}$ curve was not significantly different from the curves

TABLE 1.

Baseline parameters used in the bioeconomic assessment of integrated noble scallop Mimachlamys nobilis farming at existing small and large fish monoculture rafts in Hong Kong.

\begin{tabular}{llll}
\hline \hline \multicolumn{1}{c}{ Parameter } & Unit & Value & \multicolumn{1}{c}{ Description } \\
\hline Growth (VBGF $K$ ) & VBGF $K$ & 1.00 & Data from field trial, 1-m treatment (Table 2) \\
Grow-out duration & mo & 7 & Based on field trial and VBGF $K$ \\
Mortality & $\%$ & 53 & Data from field trial, 1-m treatment (Fig. 3) \\
Size-at-stocking & $\mathrm{mm}$ & 45 & Representing scallops ready for the final stage of grow-out \\
Size-at-harvest & $\mathrm{mm}$ & 32 & Common market size (Guo \& Luo 2016) \\
Scallops/layer at stocking & pcs & 15 & Back-calculated from anticipated mortality (33\% surface area) \\
Scallops/layer at harvest & pcs & & Reach maximum stocking density of 50\% by harvest \\
\hline
\end{tabular}



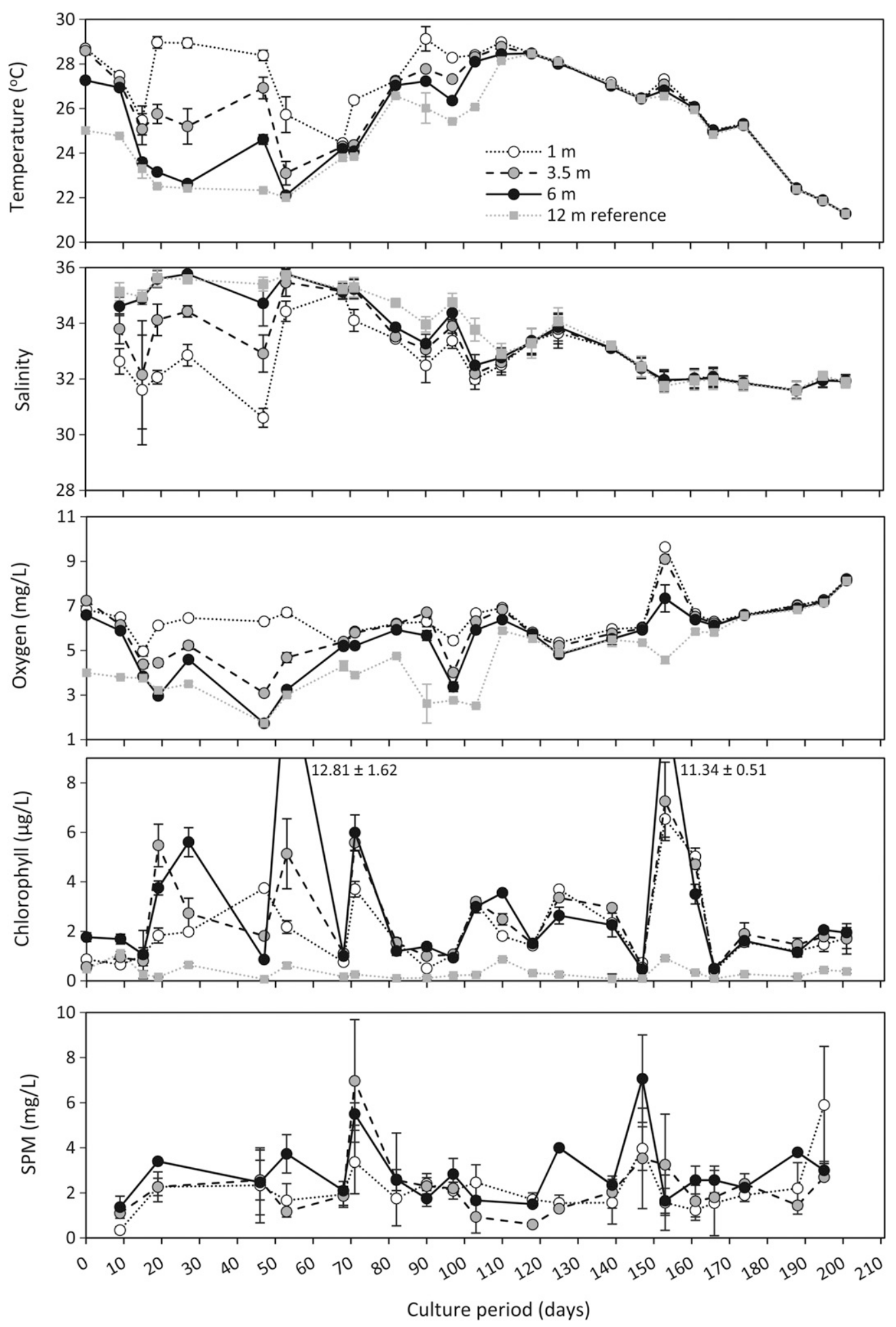

Figure 2. Temperature, salinity, oxyen, total chlorophyll, and SPM recorded at Mimachlamys nobilis treatments depths of 1-, 3.5-, and 6-m at the Kau Sai FCZ from May 29 to December 16, 2016. Reference data from 12-m are included to show environmental conditions near the sea floor.

for $1-\mathrm{m}\left(X^{2}=4.085,3\right.$ d.f., $\left.P=0.252\right)$ or $6-\mathrm{m}\left(X^{2}=2.451,3\right.$ d.f., $P=0.484) . H_{\infty}$ was highest for the $1-\mathrm{m}$ treatment $(128 \pm 21.52 \mathrm{~mm})$ but also generated the lowest growth coefficient $(K=1.00 \pm 0.28)$ (Table 2). When the VBGF was fitted with $H_{\infty}$ fixed at $120 \mathrm{~mm}$, the VBGF were still significantly different between the 1- and 6-m treatments $\left(X^{2}=13.717,2 d . f ., P=0.001\right)$, and the $3.5-\mathrm{m}$ growth curve was still not significantly different from the curves for $1-\mathrm{m}\left(X^{2}=4.187,2 d . f ., P=0.123\right)$ or $6-\mathrm{m}$ 
Feasibility of Scallop-fish Integration in South China

TABLE 2.

von Bertalanffy growth model parameter estimates (mean \pm SD) for Mimachlamys nobilis cultivated at the Kau Sai FCZ in Hong Kong.

\begin{tabular}{|c|c|c|c|c|c|c|c|}
\hline Treatment & $\begin{array}{c}\text { Height at } \\
\text { harvest }(\mathrm{mm})\end{array}$ & $\begin{array}{c}\text { SGR } \\
\left(\% \text { day }^{-1}\right)\end{array}$ & $H_{\infty}(\mathbf{m m})$ & $K$ & $t_{0}$ & $\begin{array}{l}\text { Days to reach } 80 \mathrm{~mm} \\
\text { (VBGF projection) }\end{array}$ & $\begin{array}{c}K \text { when } \\
H_{\infty}=120\end{array}$ \\
\hline $1 \mathrm{~m}^{\mathrm{a}}$ & $80.66 \pm 2.51$ & 0.29 & $128.01 \pm 21.52$ & $1.00 \pm 0.28$ & $-0.44 \pm 0.05$ & 0 & 1.14 \\
\hline $3.5 \mathrm{~m}^{\mathrm{b}}$ & $78.01 \pm 4.80$ & 0.27 & $96.96 \pm 17.58$ & $1.83 \pm 0.65$ & $-0.34 \pm 0.08$ & 26 & 1.07 \\
\hline $6 \mathrm{~m}^{\mathrm{b}}$ & $77.10 \pm 4.20$ & 0.26 & $90.89 \pm 8.98$ & $2.02 \pm 0.50$ & $-0.35 \pm 0.06$ & 59 & 0.97 \\
\hline
\end{tabular}

Common superscripts depict statistically homogenous von Bertalanffy growth functions $(\alpha=0.05)$ determined by between-treatment likelihood ratio tests.

$\left(X^{2}=2.272,2\right.$ d.f., $\left.P=0.321\right)$. The difference, however, was that the $1-\mathrm{m}$ treatment produced the highest growth coefficient $(K=1.14)$, compared with $3.5-\mathrm{m}(K=1.07)$ and 6-m $(K=0.97)$ (Fig. 3, Table 2). Shell height gains for the 1-, $3.5-$, and $6-\mathrm{m}$ treatments were $35.9 \pm 2.4,32.7 \pm 4.8$, and $31.6 \pm$ $3.7 \mathrm{~mm}$, respectively, over the 201-day culture period representing mean specific growth rates of $0.29 \%, 0.27 \%$, and $0.26 \%$ day $^{-1}$, respectively, (Table 2 ). Only scallops from the $1-\mathrm{m}$ treatment attained a mean $\mathrm{SH}$ of $80 \mathrm{~mm}$, the target sizeat-harvest in this study. Projections of the VBGF estimated that scallops in the $3.5-\mathrm{m}$ treatment would require a further 26 days of cultivation to reach $80 \mathrm{~mm} \mathrm{SH}$, whereas scallops in the 6-m treatment would require a further 59 days (Table 2). Mortality caused by transport was $12.59 \%$. Catch curve analysis for the culture period estimated total mortality $(Z)$ as $0.13,0.21$, and 0.28 for the $1-, 3.5-$, and $6-\mathrm{m}$ treatments, respectively (Fig. 4). Survival at $1-\mathrm{m}(47 \% \pm 12.5 \%)$ and $3.5-\mathrm{m}(30 \% \pm 9 \%)$ were not significantly different from each other $\left(X^{2}=1.64,1\right.$ d.f., $\left.P=0.2\right)$, but survival at $6-\mathrm{m}(17 \% \pm$ $4.5 \%)$ was significantly lower than at $1-\mathrm{m}\left(X^{2}=11.39,1 d . f\right.$., $P=0.001)$ or $3.5-\mathrm{m}\left(X^{2}=5.79,1 d . f ., P=0.02\right)$. The highest mortality occurred between the June (day 33) and August (day 90) sampling events which showed a proportional mortality of $32.6 \% \pm 12.1 \%, 45.9 \% \pm 4.0 \%$, and $65.7 \% \pm 12.6 \%$ at $1-, 3.5-$, and $6-\mathrm{m}$, respectively.

\section{Shell Biofouling Index}

The shell biofouling index for scallops collected from the August mortality event was significantly higher in the 1-m

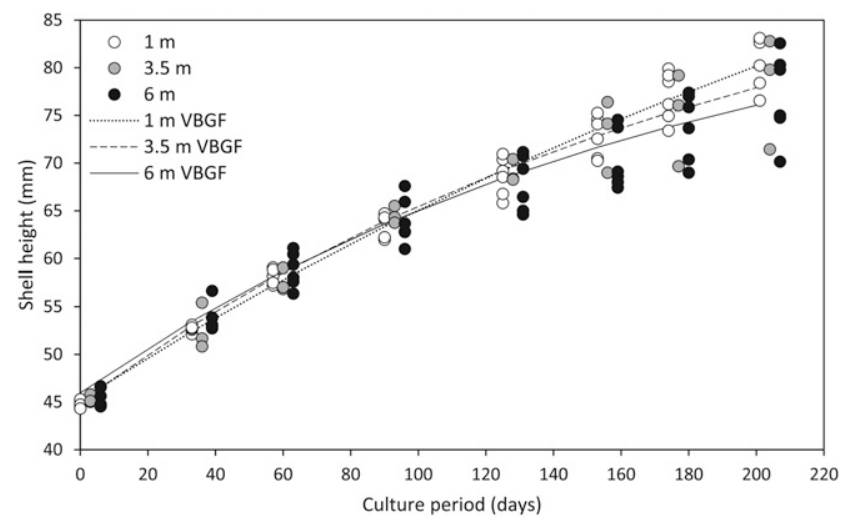

Figure 3. Observed and VBGF predicted height-at-time for Mimachlamys nobilis cultivated at the Kau Sai FCZ in Hong Kong for 201 days from May 29 to December 16, 2016. treatment $(36.45 \% \pm 9.02 \%)$ compared with $3.5-\mathrm{m}(33.55 \% \pm$ $7.47 \%)$ and $6-\mathrm{m}(25.65 \% \pm 9.84 \%)\left(F_{2,87}=12.01, P<0.001\right)$.

\section{Condition Indices}

Soft tissue condition indices were similar in June and September but changed significantly in December (Fig. 5). In December, the gonadosomatic index doubled from $11.18 \% \pm$ $3.58 \%$ in June to $22.32 \% \pm 3.79 \%\left(F_{2,88}=85.75, P<0.001\right)$, whereas the adductor muscle index decreased from $44.86 \% \pm$ $4.64 \%$ to $34.39 \% \pm 3.58 \%\left(F_{2,88}=85.07, P<0.001\right)$ (Fig. 5$)$. There was a statistically significant drop in the condition index for remaining tissue in September $\left(F_{2,88}=3.67, P=0.03\right)$, but proportionally the contribution of these tissues changed only slightly (Fig. 5).

\section{Economic Feasibility}

Expenses

The total expenses that would be incurred before the generation of revenue at the end of the first year would be US $\$ 5,485.51$ for the small farm and US\$27,659.03 for the large farm. These figures represented the value of the bank loans necessary to initiate a scallop enterprise at existing fish monoculture rafts. Capital expenses in year 0 were US\$4,573.21 and US\$23,269.03 for the small and large farm (Table 3). The purchase of lantern nets represented the bulk of total capital expenses, $40.6 \%$ (US\$1,856.00) for the small farm and $56.1 \%$ (US\$13,056.00) for the large farm. Annual operating expenses were US\$912.31 for the small farm and US\$4,390.00 for the

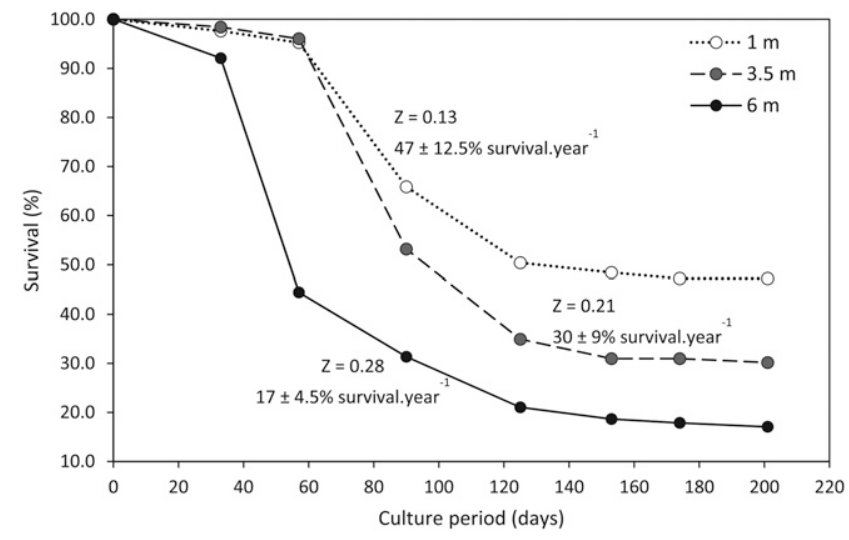

Figure 4. Survival (\%) and corresponding instantaneous rate of total mortality $(Z)$ for Mimachlamys nobilis cultivated at the Kau Sai FCZ, Hong Kong, for 201 days from May 29 to December 16, 2016. 


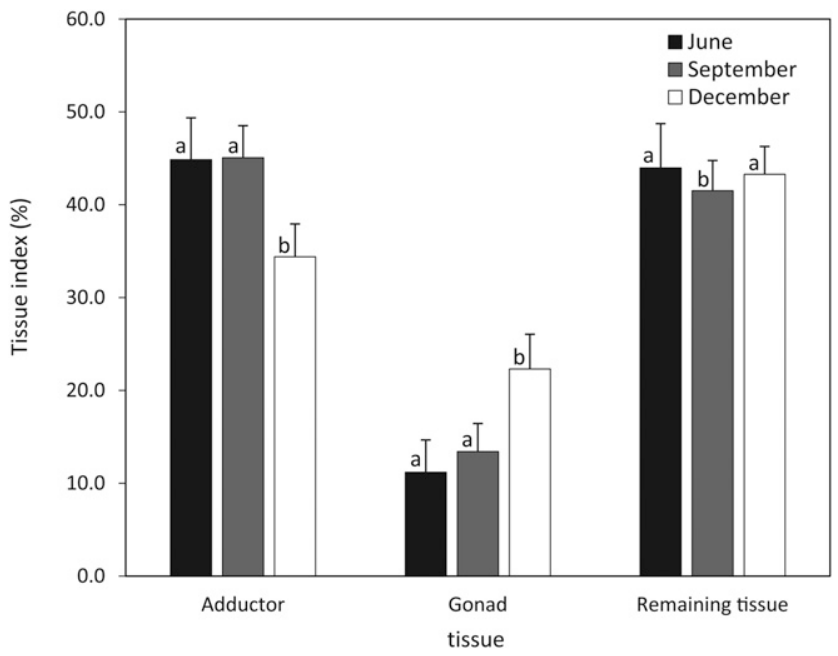

Figure 5. Adductor, gonadosomatic, and remaining soft tissue condition indices for Mimachlamys nobilis cultivated at the Kau Sai FCZ in Hong Kong for 201 days from May 29 to December 16, 2016. Common superscripts depict statistically homogenous results $(\alpha=0.05)$ determined by using one-way analysis of variance.

large farm in year 0 and increased to US\$1,297.00 and US $\$ 6,241.00$, respectively, in year 10 because of inflation (Table 4). The largest proportion of operating expenses consisted of labor which accounted for $67.9 \%$ (US\$619.23) and 68.4\% (US $\$ 3,003.85$ ) of total operating expenses for the small and large farm, respectively. The largest labor expense on the small farm was the manpower required to support the annual harvest event (US\$442.31, 48.5\%) and on the large farm it was the manpower necessary to support the bimonthly replacement of lantern nets with an annual cost of US\$1,990.38 (45.3\%). As part of the assessment, the bank loans for the small and large farm, and their 5\% annual interest, were paid off from year 1 to 5 at a rate of US\$1,267.02 and US\$6,388.54 per year, respectively.

\section{Revenue}

Revenue was generated from the end of year 1 following the first harvest. Annual harvest volumes were 1,680 catties $(1,018 \mathrm{~kg})$ and 11,900 catties $(7,211 \mathrm{~kg})$ for the small and large farm.

\section{Bioeconomic Assessment}

Cash flow projections from the 10 -y simulation predicted positive results for both farm sizes (Fig. 6). The largest annual expenses were incurred in year 0 and year 6 because of the initial purchase of lantern nets and the need to replace them after $5 \mathrm{y}$ of use (Fig. 6, Table 3). Gross revenue increased slightly over the $10-y$ period (Fig. 6). The 10-y NPV for the small farm was US $\$ 20,211.33$, which represented a $52 \%$ IRR and a DPBT of $3 \mathrm{y}$. The 10-y NPV for the large farm was US\$227,406.49, which represented a $103 \%$ IRR and a DPBT of 2 y. The sensitivity analysis of key variables showed that the NPV of the operations was robust to changes in seed price, minimum wage, lantern net price, mortality during transport, and growth rates (Fig. 7). The NPV were most sensitive to changes in total mortality during grow-out and changes in sales price. A $30 \%$ increase in the total mortality at the small farm was the only simulation that resulted in a negative $\mathrm{NPV}_{10}$ (Fig. 7).

\section{DISCUSSION}

\section{Environmental Parameters}

Water column stratification is commonly observed in inshore areas of the South China Sea through the midsummer monsoon season (Mao et al. 2011, Zhou et al. 2012). The temperature, salinity, and oxygen stratification observed at Kau Sai FCZ until mid-September is, therefore, typical for the region. The recession of stratification from mid-September onward was probably related to improved water column mixing during winter conditions (Yin 2002). The generally homogenous SPM and chlorophyll concentrations between treatment depths suggest that scallop food availability was similar between treatments, and so, food availability probably did not cause the observed differences in growth and mortality. Periodically higher chlorophyll concentrations were observed at $6 \mathrm{~m}$ compared with 1 and $3.5 \mathrm{~m}$ on days 27, 53, 110, and 153 (Fig. 2). This could have been caused by zooplankton feeding in the surface layers or the vertical migration of phytoplankton in the water column (Smayda 1997, Park et al. 2001, Tan et al. 2004). Monthly monitoring data from a government monitoring site approximately $1.5 \mathrm{~km}$ away from any fish farming showed that SPM ranged from 0.6 to $8.1 \mathrm{mg} \mathrm{L}^{-1}$ and chlorophyll-a ranged from 0.15 to $18 \mu \mathrm{g} \mathrm{L}^{-1}$ from May to December 2016 (Site PM9, EPD 2016). This is in line with the SPM concentrations of $0.35-7.07 \mathrm{mg} \mathrm{L}^{-1}$ and total chlorophyll concentrations of $0.40-12.81 \mu \mathrm{g} \mathrm{L}^{-1}$ from Kau Sai and suggests that fish farming activity did not affect these parameters at the culture zone. By December the minimum water temperature of $21.28^{\circ} \mathrm{C}$ was reached and coincided with the planned harvest (Fig. 2).

\section{Growth and Mortality}

High midsummer mortality has been accepted as a normal event during open water scallop grow-out in China (Guo et al. 1999, Xiao et al. 2005, Yu et al. 2010). In the present study, Mimachlamys nobilis showed good growth and low mortality in comparison with Chlamys farreri, the primary aquaculture scallop species in China. Xiao et al. (2005) farmed C. farreri through the peak of summer at three sites in Shandong and found that the SGR of C. farreri ranged from $0.15 \%$ to $0.91 \%$ day $^{-1}$, depending on the culture site and month. These results are comparable with the SGRs of $M$. nobilis which ranged from $0.26 \%$ to $0.29 \%$ day $^{-1}$ at Kau Sai. The mortality of $C$. farreri reported by Xiao et al. (2005) was at least $85 \%$ at all sites, comparable with the $83 \%$ mortality of $M$. nobilis in the 6-m treatment. Total mortality of the 1-m M. nobilis treatment was substantially lower at only $53 \%$.

The treatment-specific VBGF for Mimachlamys nobilis showed that the $1-\mathrm{m}$ treatment exhibited significantly better growth than 3.5- or 6-m. It is well known that food availability can affect the growth of bivalves cultured in open water (Wong \& Cheung 1999, Hawkins et al. 2002). In the present study, however, there was no apparent difference in SPM and chlorophyll concentrations between depth treatments which suggests that growth differences were probably not related to food supply. One possibility for the inferior growth in deeper water could have been the generally suboptimal environmental conditions at 3.5 and $6 \mathrm{~m}$ (Fig. 2). In particular, the periodically low oxygen concentrations could have imposed substantial physiological stress on M. nobilis in the 6-m treatment. Oxygen was generally 
Feasibility of Scallop-fish Integration in South China

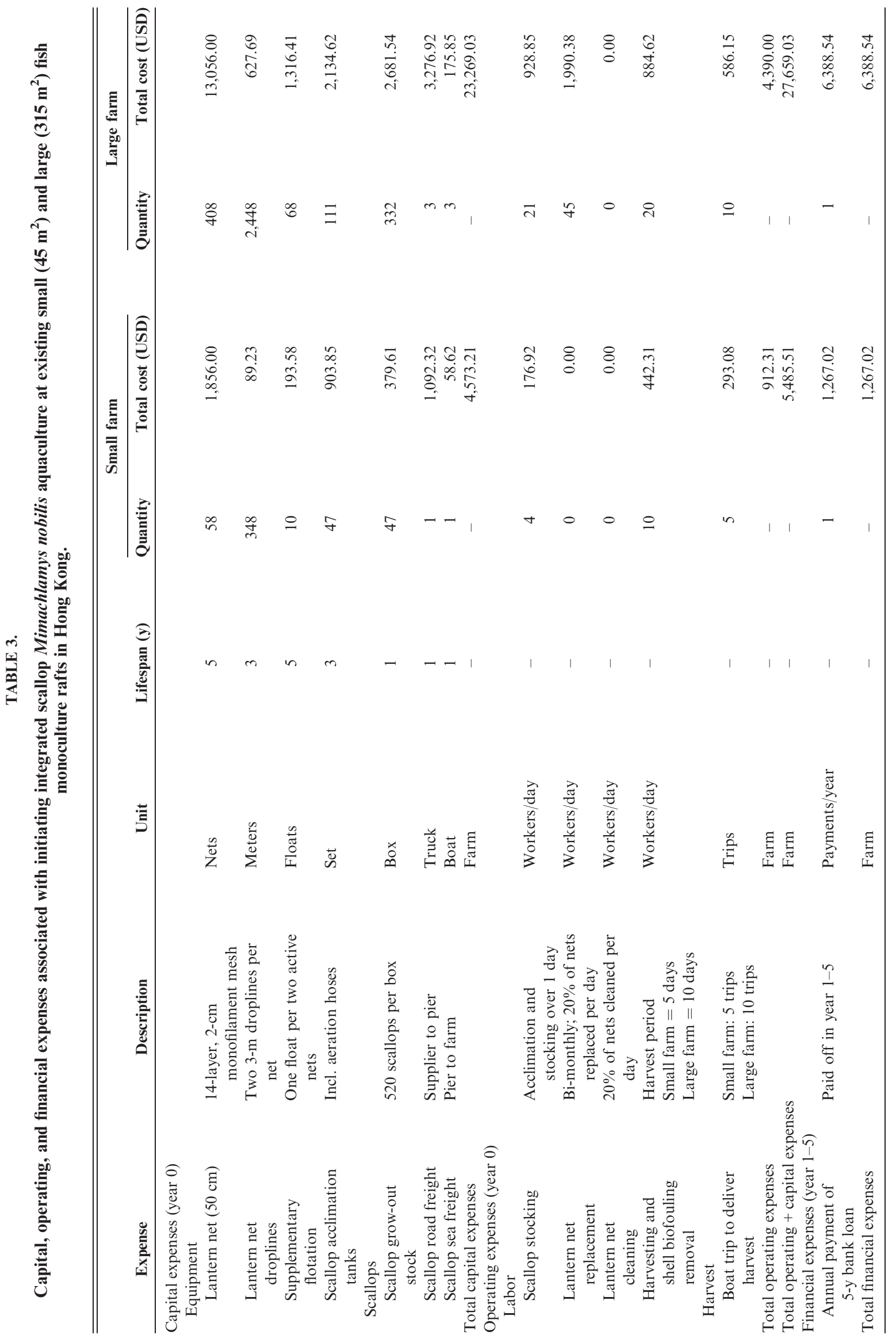


TABLE 4.

Annual cash flow (USD '000) for a Mimachlamys nobilis farming operation integrated at existing small (45 $\left.\mathrm{m}^{2}\right)$ and large (315 m²) fish monoculture farms in Hong Kong.

\begin{tabular}{|c|c|c|c|c|c|c|c|c|c|c|}
\hline \multirow[b]{2}{*}{ Year } & \multicolumn{5}{|c|}{ Small farm } & \multicolumn{5}{|c|}{ Large farm } \\
\hline & Capex & Opex & Finex & Net revenue & Net revenue $(\mathrm{PV})$ & Capex & Opex & Finex & Net revenue & Net revenue $(\mathrm{PV})$ \\
\hline 0 & 4.57 & 0.91 & 0.00 & -5.49 & -5.49 & 23.23 & 4.39 & 0 & -27.66 & -27.66 \\
\hline 1 & 1.59 & 0.95 & 1.27 & 2.75 & 2.62 & 6.35 & 4.55 & 6.93 & 27.62 & 26.30 \\
\hline 2 & 1.64 & 0.98 & 1.27 & 2.88 & 2.62 & 6.58 & 4.71 & 6.93 & 28.80 & 26.12 \\
\hline 3 & 1.70 & 1.01 & 1.27 & 3.02 & 2.61 & 6.82 & 4.88 & 6.93 & 30.02 & 25.94 \\
\hline 4 & 2.91 & 1.05 & 1.27 & 2.19 & 1.81 & 10.24 & 5.05 & 6.93 & 28.59 & 23.52 \\
\hline 5 & 1.83 & 1.09 & 1.27 & 3.32 & 2.60 & 7.31 & 5.23 & 6.93 & 32.61 & 25.55 \\
\hline 6 & 4.42 & 1.13 & 0.00 & 2.41 & 1.80 & 25.32 & 5.42 & 0 & 24.31 & 18.14 \\
\hline 7 & 3.23 & 1.17 & 0.00 & 3.64 & 2.59 & 11.38 & 5.62 & 0 & 37.81 & 26.87 \\
\hline 8 & 2.03 & 1.21 & 0.00 & 4.89 & 3.31 & 8.13 & 5.82 & 0 & 42.27 & 28.61 \\
\hline 9 & 2.10 & 1.25 & 0.00 & 5.07 & 3.27 & 8.42 & 6.03 & 0 & 43.78 & 28.22 \\
\hline 10 & 3.59 & 1.30 & 0.00 & 4.05 & 2.48 & 12.65 & 6.24 & 0 & 42.01 & 25.79 \\
\hline
\end{tabular}

Capex, capital expenses; Opex, operating expenses; Finex, finance expenses. Values are not cumulative and are adjusted for a $3.58 \%$ annual inflation. A $15 \%$ profit tax has been deducted from the net revenue values. The present value (PV) of net revenue was calculated using a $5 \%$ discount rate.

lower at $6 \mathrm{~m}$ and reached a minimum of $1.73 \mathrm{mg} \mathrm{L}^{-1}$ in mid-July. Low oxygen concentrations at Kau Sai could have resulted from the resuspension of fine sediment during monsoons and microbial respiration in deeper water (Gao et al. 2006, Zhou et al. 2006). It is also likely that oxygen concentrations would have fallen even further at night during algal respiration. It is, therefore, possible that the culture environment for $M$. nobilis at $6 \mathrm{~m}$ was suboptimal. These findings have important implications for industry because the VBGF projections estimated that the 3.5- and 6-m scallop treatments would require up to two additional months to reach an $80 \mathrm{~mm} \mathrm{SH}$. The additional time required for grow-out would impose additional expenses on farmers and may necessitate the continued cultivation of $M$. nobilis through midwinter when water temperatures fall below the optimal range for $M$. nobilis grow-out, estimated at $20^{\circ} \mathrm{C}-25^{\circ}$ C (Guo \& Luo 2016).

In the present study there was a significant increase in the mortality of Mimachlamys nobilis with increasing depth from 1 to $6 \mathrm{~m}$. Lodeiros et al. (1998) found that mortality in the tropical scallop Lyropecten nodusus (Linnaeus, 1758) was different between treatments at 8,21 , and $36 \mathrm{~m}$ and hypothesized that the differences were due to different growth environments between depths, leading to differences in temperature, reproductive stress, shell biofouling, and the density of toxic dinoflagellates. Lodeiros et al. (1998) concluded that the overall growth environment was different between depths. In the present study there were substantial differences in temperature, salinity, and oxygen between depths from May to September suggesting that the different growth and mortality between treatments was probably caused by different growth environments during midsummer. In particular, it is likely that the low oxygen concentrations at 3.5 and $6 \mathrm{~m}$ through midsummer was a leading cause of the higher mortality observed at those depths. One further mortality-related observation can be made; the inflow of fresh water during heavy summer monsoons did increase mortality at $1-\mathrm{m}$. This is relevant because the perception among fish farmers in Hong Kong is that it is not possible to farm sedentary species like $M$. nobilis because monsoon rain is likely to cause total stock loss. Previous experimental trials with $M$. nobilis have shown that the species is tolerant to a wide range of salinities from 24.3 to 37.2 (Zhang et al. 2008). Therefore, the high survival of $M$. nobilis at $1 \mathrm{~m}$ compared with those at 3.5 and $6 \mathrm{~m}$ shows that mortality was not unduly influenced by surface salinity flux.

The relatively high mortality of Mimachlamys nobilis observed during midsummer in all treatments was not associated with any abnormal mortality of the fish at any farms at Kau Sai. High midsummer mortality of scallops farmed in China was first observed in Chlamys farreri in 1994 and has been accepted as a normal part of husbandry (Guo et al. 1999, Xiao et al. 2005, Yu et al. 2010). No previous study has been able to pinpoint the causes of these annual mortality events but it has been hypothesized that they could result from a combination of generally adverse environmental conditions including high temperature, water body overuse, scallop raft overcrowding, reduced scallop immunity in summer, opportunistic predators or pathogens, and stress during reproduction (Zhang \& Yang 1999, Xiao et al. 2005, Yu et al. 2010). The measures that have been recommended for minimizing annual mortality have included maintaining responsible stocking densities, maintaining healthy seed stock, extending culture to areas with depths greater than $20 \mathrm{~m}$, and improving scallop germplasm, but the benefits of these measures remain undemonstrated at any large scale (Yang et al. 1999, Zhang \& Yang 1999). Until further research can identify practical methods to minimize mortality, high stock losses in summer should be accepted as a normal part of $M$. nobilis husbandry and must be accounted for when calculating stock requirements to ensure that target harvests are met.

One of the potential benefits of integrating scallops with fed finfish is that by-products from fish feeding can increase scallop food availability which could lead to improved scallop growth (Stirling \& Okumus 1995, Barrington et al. 2009). Dissolved inorganic nutrients released from fish can promote the proliferation of dietary microalgae and it is possible that scallops could directly assimilate uneaten fish feed or fish feces (Parsons et al. 2002, Sarà et al. 2009). Although the present study has shown the financial advantage of integrating Mimachlamys 
Feasibility of Scallop-fish Integration in South China
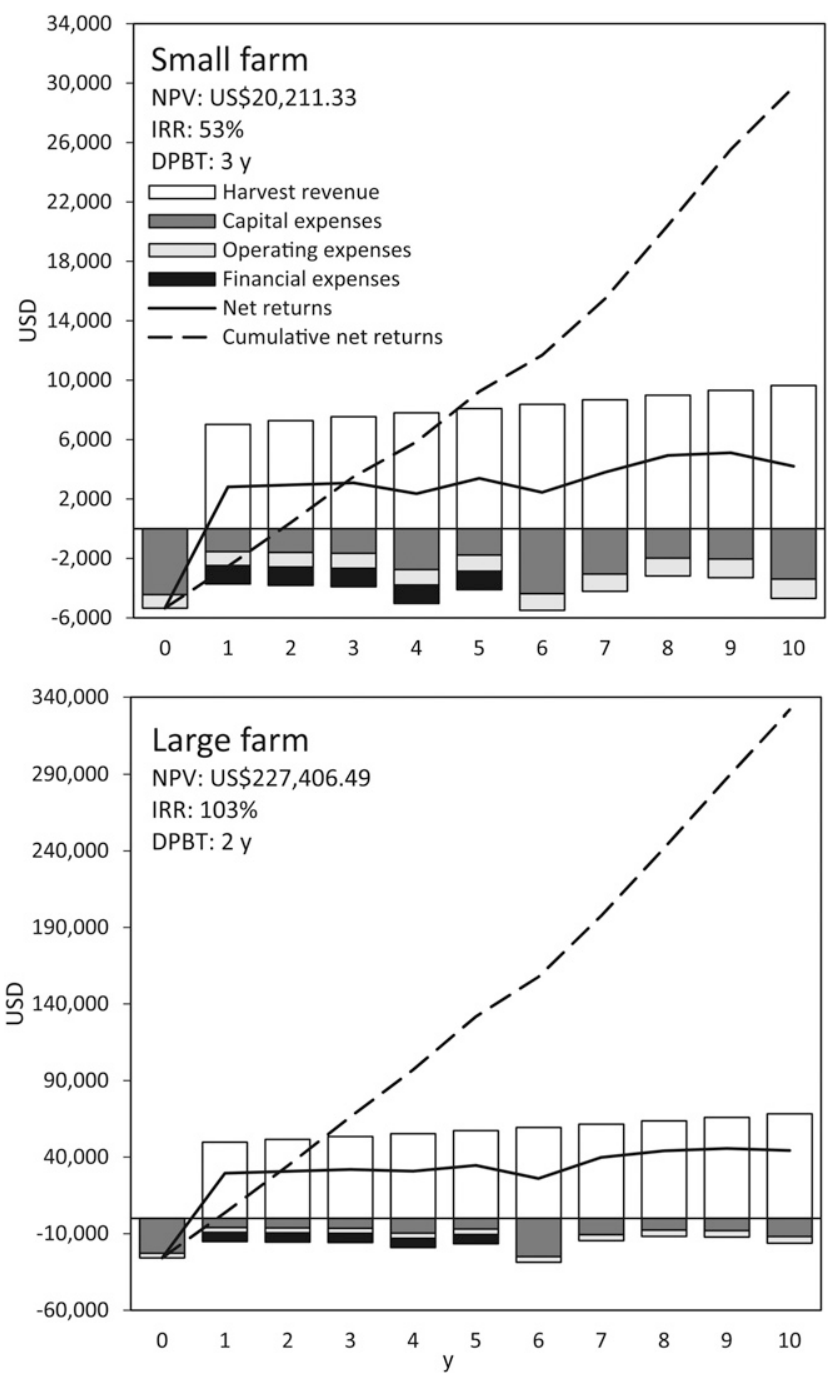

Figure 6. The 10-y cash flows (U.S. dollars), NPV, IRR, and DPBT results for the integration of the scallop Mimachlamys nobilis at existing small $\left(45 \mathrm{~m}^{2}\right)$ and large $\left(315 \mathrm{~m}^{2}\right)$ fish monoculture rafts in Hong Kong.

nobilis from the perspective of fish monoculture operations, future work should investigate any potential growth advantages to $M$. nobilis integrated at fish farms compared with $M$. nobilis produced at scallop monoculture sites. In addition, filter feeders are considered extractive species that may help to remediate some of the organic waste released from fish farms (Parsons et al. 2002, Cranford et al. 2013). Future work should attempt to quantify the bioremediation capabilities of $M$. nobilis for extracting the organic waste from suspended mariculture (Parsons et al. 2002).

\section{Shell Biofouling Index}

The settlement of fouling organisms on shells and culture gear is problematic because fouling can decrease growth and product marketability while increasing mortality and the labor required to process scallops before distribution (Watson et al. 2009, Adams et al. 2011, Qi et al. 2014). Previous work has shown that decreased growth and increased mortality occur when severe fouling inhibits food and oxygen supply, serves as a habitat for predatory invertebrates such as crabs, and acts as a vector for pathogens (Lesser et al. 1992, Freites et al. 2000, Wu et al. 2003, Sievers et al. 2013). In the present study, the 1-m treatment exhibited the highest level of biofouling but this was also the treatment that had the best growth and survival. This suggests that biofouling was not the root cause of the lower production performance observed at $6 \mathrm{~m}$. The higher biofouling load in the 1-m treatment could be due to better environmental conditions in the upper water column, resulting in increased settlement success by fouling invertebrates (Claereboudt et al. 1994, Taylor et al. 2006). In the United States, fouling of cultured bivalves is accepted as part of normal husbandry - the average farm-level cost of biofouling was estimated by countrywide surveys at $14.7 \%$ of farm revenue (Adams et al. 2011). Expenditure went to husbandry efforts to reduce fouling and measures to remove fouling during processing. In this study, fouling was not a major financial concern for the small or large farm because it was removed as part of processing during harvest. Processing was handled by existing farm labor and the help of two part-time workers on each harvest day (Table 3). As fouling was not the cause of increased mortality, and was not associated with high costs, fouling can be accepted as part of Mimachlamys nobilis husbandry until cost-effective methods to eliminate fouling can be developed.

\section{Condition Indices}

The doubling of the gonadosomatic index of Mimachlamys nobilis in December, and the $25 \%$ decrease of the adductor index, coincided well with the planned harvest time. Gonad maturation with decreasing temperature has been reported for the bivalve Atrina maura (Sowerby, 1835) because lower temperatures facilitate a longer vitellogenic phase (RodríguezJaramillo et al. 2001). The decrease in the proportional contribution of the adductor muscle observed in $M$. nobilis in December is typical in scallops because ripe gonads make a disproportionately large contribution to soft tissue indices and because of the high energy demands of gamete production (Pazos et al. 1997, Mendo et al. 2011). A full gonad is necessary to insure good product marketability in China and so the favorable soft tissue indices confirm that December is an appropriate month to harvest $M$. nobilis each year.

\section{Economic Feasibility}

This study showed that physically integrating Mimachlamys nobilis at existing fish rafts in Hong Kong is technically feasible because the scallops grew to optimal market size $(80 \mathrm{~mm} \mathrm{SH})$ from June to December with sufficiently low mortality to warrant a comprehensive economic feasibility assessment. Cost calculations showed that it would cost US\$5,485.51 to initiate scallop farming at a small fish farm $\left(45 \mathrm{~m}^{2}\right)$ and US\$27,659.03 at a large fish farm $\left(315 \mathrm{~m}^{2}\right)$. The economic simulations showed that, despite high midsummer mortality, start-up capital could be recovered within 3 y (Fig. 6).

\section{Expenses}

The scallop farming enterprise benefitted from the existing infrastructure of the fish monoculture operation. Start-up expenditure was, therefore, low compared with studies that established entirely new operations (e.g., Choi et al. 2006, Taylor et al. 2006, Mendo et al. 2011). Ongoing annual operating expenses were also low because scallops do not 
Growth (K) $+30 \%$ (1.30)

Growth (K) $-30 \%(0.70)$

Transport mortality $+30 \%(0.156)$

Transport mortality $-30 \%$ (0.084)

Seed price $+30 \%$ (US\$20.00/1000 scallop) Seed price $-30 \%$ (US\$10.76/1000 scallop)

Lantern net price $+30 \%$ (US\$19.6/net) Lantern net price -30\% (US\$36.4/net)

Minimum wage $+30 \%$ (US\$6.3/h) Minimum wage $-30 \%$ (US\$3.4/h)

Sales price $+30 \%$ (US\$8.24/606g catty) Sales price $-30 \%$ (US\$4.44/606g catty)

Mortality (Z) $+30 \%(0.719)$ Mortality (Z) $-30 \%$ (0.375)

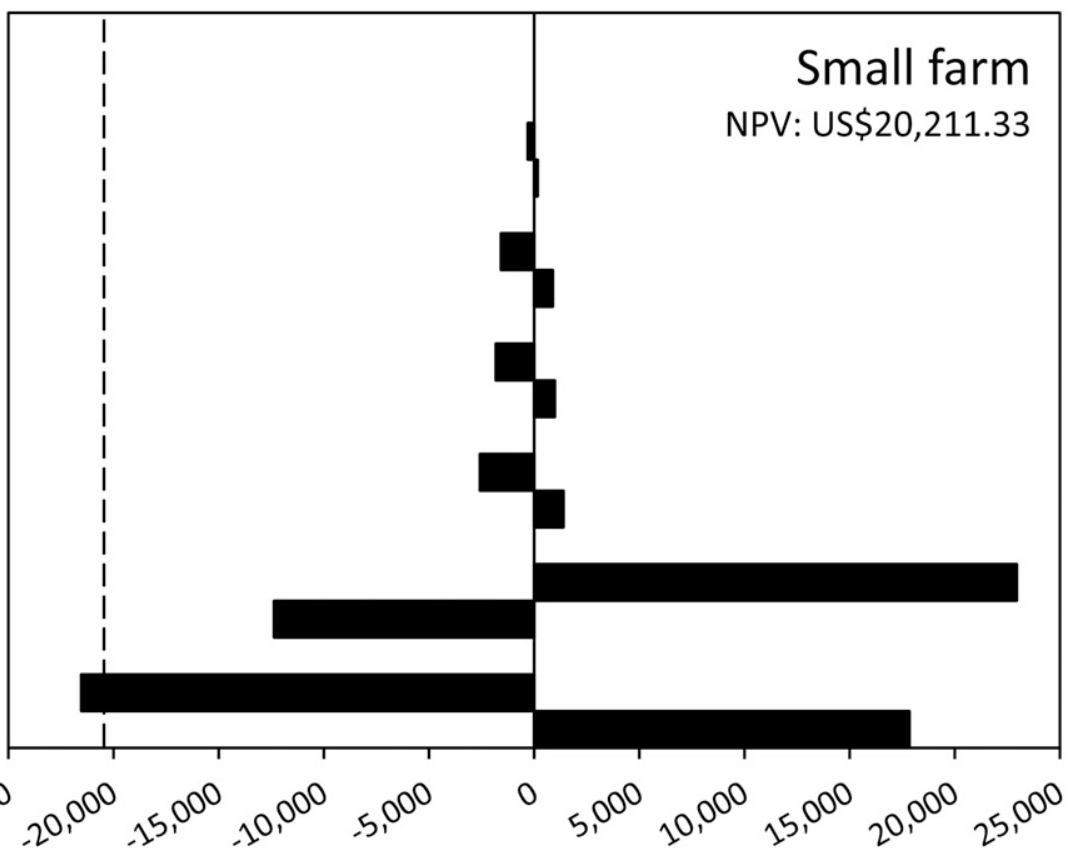

Growth (K) $+30 \%(1.30)$ Growth (K) $-30 \%(0.70)$

Transport mortality $+30 \%(0.156)$ Transport mortality $-30 \%(0.084)$

Seed price $+30 \%$ (US\$20.00/1000 scallop) Seed price $-30 \%$ (US\$10.76/1000 scallop)

Lantern net price $+30 \%$ (US\$19.6/net) Lantern net price $-30 \%$ (US\$36.4/net)

Minimum wage $+30 \%$ (US\$6.3/h) Minimum wage $-30 \%$ (US\$3.4/h)

Sales price $+30 \%$ (US\$8.24/606g catty) Sales price $-30 \%$ (US\$4.44/606g catty)

Mortality (Z) $+30 \%(0.719)$
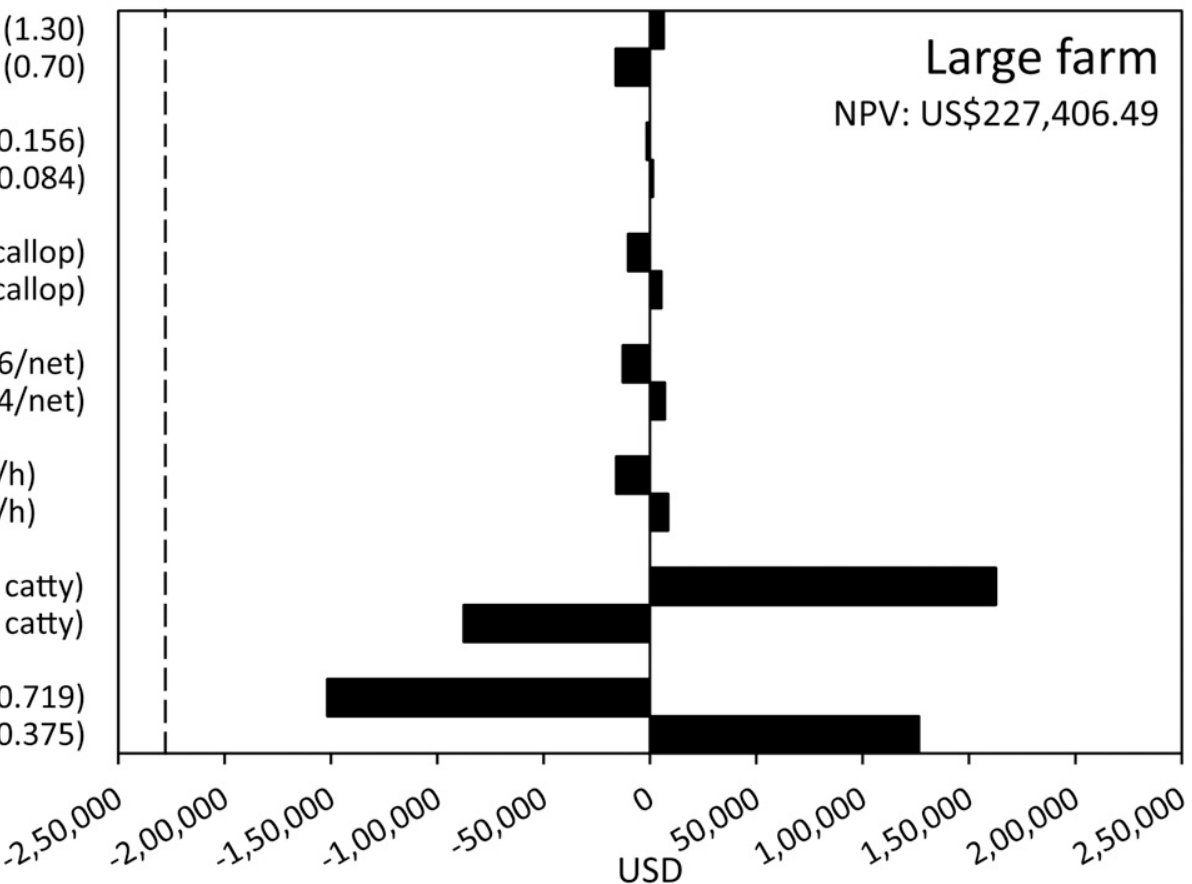

Figure 7. Sensitivity analysis of the U.S. dollar change in the NPV 10 for a 10-y integrated Mimachlamys nobilis operation at existing fish monoculture farms in Hong Kong. The dashed line depicts the point at which the NPV 10 would be negative.

require feed inputs. The requirements for supplementary labor were low because the most frequent husbandry activity was the routine replacement and cleaning of fouled lantern nets which needs to be performed bimonthly based on observed biofouling loads at Kau Sai FCZ. On the small farm, which integrated 48 active lantern nets, net cleaning and replacement could be covered by existing farm labor. On the large farm, 45 worker days were required per year to cover the additional labor associated with this task, representing a relatively small expense in comparison with the revenue generated (Table 3 ).
Revenue

From the end of year 1, the scallop enterprises generated positive net revenues with an annual present value ranging from $\$ 1,852.00$ to $\$ 3,365.00$ for the small farm and from $\$ 18,142.00$ to $\$ 28,611.00$ for the large farm (Table 4$)$. These values represent a considerable annual increase in liquidity for relatively small-scale fish farms that are traditional, family-based operations. Given that the weight of the fish farmed in Hong Kong in 2014 accounted for only $2 \%$ of the weight of fish 
consumed, it is possible that the industry needs additional sources of income to help sustain fish farming operations and promote progress toward modern aquaculture (Lai et al. 2016). The additional revenue from an integrated scallop enterprise could help provide the capital necessary to achieve this. In addition, the simulations that were run in the present study did not increase the total scallop production volume over the $10-y$ assessment period. This was a precautionary measure because a scallop enterprise would be a first for Hong Kong and so the effects of more intensive production are not predictable (Shi et al. 2013). In future work there is scope for expansion. The apparent increase in gross revenue over the $10 \mathrm{y}$ resulted from the $3.58 \%$ inflation rate.

\section{Bioeconomic Assessment}

Existing farm infrastructure and labor substantially reduced the expenditure necessary to initiate a scallop enterprise and so simulations returned favorable NPV and IRR values, and short DPBT. Over the 10-y operation, the largest expenses were incurred in year 0 and year 6 because of the initial purchase and subsequent replacement of scallop lantern nets at the end of their useful life.

The positive NPV for both farms suggests that it is worth proceeding with integrated scallop farming at existing fish monoculture rafts in Hong Kong and so further research and development is warranted (Engle 2010, Di Trapani et al. 2014). This is supported by the high IRR which indicates that scallop operations would be profitable because IRR values are substantially higher than the opportunity cost of capital, typically taken as 10\% (Engle 2010). The IRR of 52\% for the small farm and $103 \%$ for the large farm are higher than the IRR calculated in similar scallop production studies. Penney and Mills (2000) reported IRR from $-9.9 \%$ to $39.4 \%$ for a Placopecten magellanicus (Gmelin, 1791) operation in Newfoundland, Canada. Taylor et al. (2006) reported IRR of $21.6 \%-27.0 \%$ for the scallop Nodipecten subnodosus (Sowerby, 1835) cultivated on the Baja California Peninsula. The comparatively lower IRR from these studies is probably because they had to construct their culture systems without existing infrastructure or labor. The DPBT estimated that the time to recoup the initial investments was $3 \mathrm{y}$ for the small farm and $2 \mathrm{y}$ for large farm, about half the time required to recoup the initial investment in an Atrina maura farm in Mexico which was estimated at 6-7 y (Mendo et al. 2011). The shorter DPBT of the large farm compared with the small farm is due to economies of scale; there is a proportionate saving in costs gained from an increased level of production. The large farm is approximately seven times larger than the small farm but has an NPV that is approximately 10 times higher. Economies of scale is common in aquaculture and has been demonstrated previously for bivalves (Penney \& Mills 2000, Mendo et al. 2011).

The sensitivity analysis showed that the scallop enterprise was robust to changes in lantern net price, seed stock price, transport mortality, and growth rates but was somewhat sensitive to changes in mortality and market price (Fig. 7). Changes in growth rate made no apparent change to the NPV of the small farm and had only a slight influence on the NPV of the large farm. The month-to-month husbandry expenses for Mimachlamys nobilis are small in comparison with the revenue generated and so a potential decrease in growth rates, that would extend the culture duration, would change the NPV only slightly. It is important, however, to consider that the water temperature after December usually drops below the optimal conditions for $M$. nobilis growth which may extend the necessary culture duration further still. The $M$. nobilis enterprises were robust to changes in the minimum wage because the additional labor requirements of the scallop operations were small. Changes to transport mortality and the price of grow-out seed stock had a very small impact on the NPV because the annual purchase of seed, and the transport of that seed, made little contribution to the overall cost of the business (Table 3). In the event of considerably higher mortality during transport, it would be cost-effective to add more seed to a shipment, or to order an additional shipment of seed, to mitigate any large mortality events that may occur during transport. Despite the high capital cost of the lantern nets, and their large contribution to cash outflow in year 0 and year 6 , the operation was relatively robust to changes in lantern net price because the depreciation of the nets was spread across the full $5 \mathrm{y}$ of useful life. The 10-y NPV was most sensitive to changes in sales price and mortality, probably because these parameters directly impacted the bottom line of the enterprise. This is a common finding in aquaculture businesses that are dependent on producing a critical biomass to insure farm profitability (Stirling \& Okumus 1995, Taylor et al. 2006, Fonseca et al. 2017). A 30\% increase in mortality over the $10-y$ simulation of the small farm was the only variation that resulted in a negative NPV. In any farm situation a $30 \%$ increase in mortality would be critical. In this study, however, the existing farm infrastructure absorbed some of the major costs of the scallop enterprise which helped to buffer the impact of mortality. Still, it should be noted that the scallop systems were somewhat sensitive to changes in mortality which is an important consideration when assessing whether to proceed with integrated scallop farming. This is relevant to the present study because relatively small changes in depth from 1 to $6 \mathrm{~m}$ caused a significant increase in mortality and the causes of mortality cannot be easily controlled. There are, however, measures which could be taken to minimize the financial risks associated with mortality. One possibility would be to increase the initial stocking density from 32 scallops/layer (33\% surface area), which was used in the economic assessment based on anticipated mortality and the target harvest volumes, to 42 scallops/layer (45\% surface area), which was used in the field trial. Future work could look to increase scallop stocking densities as high as $60 \%-80 \%$. These higher densities are commonly used in scallop farming in China and could offer some insurance against midsummer and depth-related mortality given the low cost of scallop seed and the low sensitivity of these operations to changes in seed price (Fig. 7). If higher than anticipated mortality occurs, then the higher stocking density would help to buffer losses. If higher mortality does not occur, then farmers could opt to redistribute surplus scallops to nearby farms, sell surplus scallops at suboptimal sizes, accept potentially reduced growth rates from overcrowding, or cull surplus scallops.

\section{CONCLUSIONS}

This baseline study has shown that physically integrating Mimachlamys nobilis at existing fish monoculture farms in Hong Kong is technically and economically feasible. Despite 
the low stocking densities used as a precautionary measure in the field trial, the bioeconomic assessment showed that the operations were profitable because $M$. nobilis grew well and showed sufficient survival to size-at-harvest. The different growth and mortality observed between depth treatments suggests that changes in the growth environment from 1 to $6 \mathrm{~m}$ could significantly impact production. As the fish rafts in Hong Kong have operated under a monoculture model for more than $50 \mathrm{y}$, the alternative to an integrated scallop enterprise would be the "do nothing" option. Integrated scallop farming is, therefore, recommended because the simulations of 10-y operations produced high NPV and IRR, and short DPBT for the two farm sizes assessed. The sensitivity analysis showed that the proposed scallop enterprises were robust to changes in most key variables and were moderately sensitive to changes in sales price and stock mortality. On the one hand the sensitivity analysis identified that there is some inherent risk in the proposed scallop operation because changes to sales price and stock mortality cannot be easily controlled. On the other, integrating scallops would add a new trophic level to farm operations that would help to increase farm output and diversify production, thereby reducing risk at the farm level.

\section{ACKNOWLEDGMENTS}

This work was supported by the Sustainable Fisheries Development Fund of the Hong Kong Agriculture Fisheries and Conservation Department (SFDF-0016), the Shenzhen Key Laboratory Program of Science, Technology and Innovation Commission of the Shenzhen Municipality, China (ZDSYSY20140509155229806), and the Sustainable Ecological Aquaculture project of the City University of Hong Kong (No. 9610320). The authors thank Prof. Caihuan Ke from Xiamen University for supplying the scallops used in this study. Thanks to Mr. Likun Wei and Mr. Feng Zhang, City University of Hong Kong, for their assistance in the field.

\section{LITERATURE CITED}

Adams, C. M., S. E. Shumway, R. B. Whitlatch \& T. Getchis. 2011. Biofouling in marine molluscan shellfish aquaculture: a survey assessing the business and economic implications of mitigation. $J$. World Aquacult. Soc. 42:242-252.

Barrington, K., T. Chopin \& S. Robinson. 2009. Integrated multitrophic aquaculture (IMTA) in marine temperate waters. In: Soto, D., editor. Integrated mariculture: a global review. FAO Fisheries Technical Paper No. 529. Rome, Italy: FAO. pp. 7-46.

Buckland, S. T. 1984. Monte Carlo confidence intervals. Biometrics 40:811-817.

Cao, L., W. Wang, Y. Yang, C. Yang, Z. Yuan, S. Xiong \& J. Diana. 2007. Environmental impact of aquaculture and countermeasures to aquaculture pollution in China. Environ. Sci. Pollut. Res. Int. 14:452-462.

Chen, J., C. Guang, H. Xu, Z. Chen, P. Xu, X. Yan, Y. Wang \& J. Liu. 2007. A review of cage and pen aquaculture: China. In: Halwart, M., D. Soto \& J. R. Arthur, editors. Cage aquaculture-regional reviews and global overview. FAO Fisheries Technical Paper No. 498. Rome, Italy: FAO. pp. 53-66.

Choi, J. D., S. L. Larkin \& T. H. Spreen. 2006. A bioeconomic model for cham scallop (Patinopecten yessoensis) aquaculture in Korea. Aquac. Econ. Manag. 10:125-146.

Chopin, T. 2015. Marine aquaculture in Canada: well-established monocultures of finfish and shellfish and an emerging integrated multi-trophic aquaculture (IMTA) approach including seaweeds, other invertebrates, and microbial communities. Fisheries (Bethesda, Md.) 40:28-31.

Chopin, T., C. Yarish, R. Wilkes, E. Belyea \& S. Lu. 1999. Salmon integrated aquaculture for bioremediation and diversification of the aquaculture industry. J. Appl. Phycol. 11:463-472.

Claereboudt, M. R., D. Bureau, J. Côté \& J. H. Himmelman. 1994. Fouling development and its effect on the growth of juvenile giant scallops (Placopecten magellanicus) in suspended culture. Aquaculture 121:327-342.

Cranford, P. J., G. K. Reid \& S. M. C. Robinson. 2013. Open water integrated multi-trophic aquaculture: constraints on the effectiveness of mussels as an organic extractive component. Aquacult. Environ. Interact. 4:163-173.

Di Trapani, A. M., F. Sgroi, R. Testa \& S. Tudisca. 2014. Economic comparison between offshore and inshore aquaculture production systems of European sea bass in Italy. Aquaculture 434:334-339.

Efron, B. 1982. The jacknife, the bootstrap and other resampling plans. Philadelphia, PA: Society for Industrial and Applied Mathematics. $92 \mathrm{pp}$.
Engle, C. R. 2010. Aquaculture economics and financing: management and analysis. Ames, IA: Wiley-Blackwell. 260 pp.

EPD. 2016. Marine water quality in Hong Kong in 2016. Hong Kong, China: Environmental Protection Department. 152 pp.

Fang, J., H. Sun, J. Yan, G. F. Newkirk \& J. Grant. 1996. Polyculture of scallop Chlamys farreri and kelp Laminaria japonica in Sungo Bay. Chin. J. Oceanology Limnol. 14:322-329.

Ferreira, J. G., A. Sequeira, A. J. S. Hawkins, A. Newton, T. D. Nickell, R. Pastres, J. Forte, A. Bodoy \& S. B. Bricker. 2009. Analysis of coastal and offshore aquaculture: application of the FARM model to multiple systems and shellfish species. Aquaculture 292:129-138.

Fonseca, T., F. S. David, F. A. S. Ribeiro, A. A. Wainberg \& W. C. Valenti. 2017. Technical and economic feasibility of integrating seahorse culture in shrimp/oyster farms. Aquacult. Res. 48:655-664.

Freites, L., J. H. Himmelman \& C. J. Lodeiros. 2000. Impact of predation by gastropods and crabs recruiting onto culture enclosures on the survival of the scallop Euvola ziczac (L.) in suspended culture. J. Exp. Mar. Biol. Ecol. 244:297-303.

Gao, Q. F., P. K. S. Shin, G. H. Lin, S. P. Chen \& G. C. Siu. 2006. Stable isotope and fatty acid evidence for uptake of organic waste by greenlipped mussels Perna viridis in a polyculture fish farm system. Mar. Ecol. Prog. Ser. 317:273-283.

González, M. L., M. C. Pérez \& D. A. López. 2002. Breeding cycle of the northern scallop, Argopecten purpuratus (Lamarck, 1819) in southern Chile. Aquacult. Res. 33:847-852.

Guo, X. \& Y. Luo. 2006. Scallop culture in China. In: Shumway, S. E. \& G. J. Parsons, editors. Scallops: biology, ecology and aquaculture, $2^{\text {nd }}$ edition. Boston, MA: Elsevier Science. pp. 1143-1161.

Guo, X. \& Y. Luo. 2016. Scallops and scallop aquaculture in China. In: Shumway, S. E. \& G. J. Parsons, editors. Scallops: biology, ecology and aquaculture, $3^{\text {rd }}$ edition. Boston, MA: Elsevier Science. pp. 937952.

Guo, X. M., S. E. Ford \& F. S. Zhang. 1999. Molluscan aquaculture in China. J. Shellfish Res. 18:19-31.

Hawkins, A. J. S., P. Duarte, J. G. Fang, P. L. Pascoe, J. H. Zhang, X. L. Zhang \& M. Y. Zhu. 2002. A functional model of responsive suspension-feeding and growth in bivalve shellfish, configured and validated for the scallop Chlamys farreri during culture in China. $J$. Exp. Mar. Biol. Ecol. 281:13-40.

Kaplan, E. L. \& P. Meier. 1958. Nonparametric estimation from incomplete observations. J. Am. Stat. Assoc. 53:457-481.

Lai, R. W. S., M. J. Perkins, K. K. Y. Ho, J. C. Astudillo, M. M. N. Yung, B. D. Russell, G. A. Williams \& K. M. Y. Leung. 2016. Hong 
Kong's marine environments: history, challenges and opportunities. Reg. Stud. Mar. Sci. 8:259-273.

Lesser, M. P., S. E. Shumway, T. Cucci \& J. Smith. 1992. Impact of fouling organisms on mussel rope culture: interspecific competition for food among suspension-feeding invertebrates. J. Exp. Mar. Biol. Ecol. 165:91-102.

Lodeiros, C. J., J. J. Rengel, L. Freites, F. Morales \& J. H. Himmelman. 1998. Growth and survival of the tropical scallop Lyropecten (Nodipecten) nodosus maintained in suspended culture at three depths. Aquaculture 165:41-50.

Lü, W., W. Li, C. Ke \& H. Wang. 2017. Reproductive success under the joint influences of temperature and salinity in noble scallop, Chlamys nobilis (Reeve). Aquacult. Res. 48:686-696.

Mantel, N. 1966. Evaluation of survival data and two new rank order statistics arising in its consideration. Cancer Chemother. Rep. $50: 163-170$

Mendo, T., V. Koch, M. Wolff, F. Sínsel \& C. Ruiz-Verdugo. 2011. Feasibility of intertidal bottom culture of the penshell Atrina maura in Bahia Magdalena, Baja California Sur, Mexico. Aquaculture 314:252-260.

Neori, A., T. Chopin, M. Troell, A. H. Buschmann, G. P. Kraemer, C. Halling, M. Shpigel \& C. Yarish. 2004. Integrated aquaculture : rationale, evolution and state of the art emphasizing seaweed biofiltration in modern mariculture. Aquaculture 231:361-391.

Nobre, A. M., D. Robertson-Andersson, A. Neori \& K. Sankar. 2010. Ecological-economic assessment of aquaculture options: comparison between abalone monoculture and integrated multi-trophic aquaculture of abalone and seaweeds. Aquaculture 306:116-126.

Nunes, J. P., J. G. Ferreira, F. Gazeau, J. Lencart-Silva, X. L. Zhang, M. Y. Zhu \& J. G. Fang. 2003. A model for sustainable management of shellfish polyculture in coastal bays. Aquaculture 219:257-277.

Park, J. G., M. K. Jeong, J. A. Lee, K.-J. Cho \& O.-S. Kwon. 2001. Diurnal vertical migration of a harmful dinoflagellate, Cochlodinium polykrikoides (Dinophyceae), during a red tide in coastal waters of Namhae Island, Korea. Phycologia 40:292-297.

Parsons, G. J., S. E. Shumway, S. Kuenstner \& A. Gryska. 2002. Polyculture of sea scallops (Placopecten magellanicus) suspended from salmon cages. Aquacult. Int. 10:65-77.

Pazos, A. J., G. Román, C. P. Acosta, M. Abad \& J. L. Sánchez. 1997. Seasonal changes in condition and biochemical composition of the scallop Pecten maximus L. from suspended culture in the Ría de Arousa (Galicia, N.W. Spain) in relation to environmental conditions. J. Exp. Mar. Biol. Ecol. 211:169-193.

Penney, R. W. \& T. J. Mills. 2000. Bioeconomic analysis of a sea scallop, Placopecten magellanicus, aquaculture production system in Newfoundland, Canada. J. Shellfish Res. 19:113-124.

Qi, Z., J. Wang, Y. Mao, J. Zhang, Z. Jiang \& J. Fang. 2014. Use of the sea urchin Hemicentrotus pulcherrimus for biological control of fouling in suspended scallop cultivation in Northern China. Aquaculture 420-421:270-274.

Qian, P. Y., C. Y. Wu, M. Wu \& Y. K. Xie. 1996. Integrated cultivation of the red alga Kappaphycus alvarezii and the pearl oyster Pinctada martensi. Aquaculture 147:21-35.

Ricker, W. E. 1975. Computation and interpretation of biological statistics of fish populations. Bull. Fish. Res. Board Can. 191:1-382.

Ridler, N., M. Wowchuk, B. Robinson, K. Barrington, T. Chopin, S. Robinson, F. Page, G. Reid, M. Szemerda, J. Sewuster \& S. BoyneTravis. 2007. Integrated multi-trophic aquaculture (IMTA): a potential strategic choice for farmers. Aquac. Econ. Manag. 11:99-110.

Rodríguez-Jaramillo, C., A. N. Maeda-Martínez, M. E. Valdez, T. Reynoso-Granados, P. Monsalvo-Spencer, D. Prado-Ancona, F. Cardoza-Velasco, M. Robles-Mungaray \& M. T. Sicard. 2001. The effect of temperature on the reproductive maturity of the penshell Atrina maura (Sowerby, 1835) (Bivalvia: Pinnidae). J. Shellfish Res. 20:39-47.

Sarà, G., A. Zenone \& A. Tomasello. 2009. Growth of Mytilus galloprovincialis (mollusca, bivalvia) close to fish farms: a case of integrated multi-trophic aquaculture within the Tyrrhenian Sea. Hydrobiologia 636:1-8.

Sarkis, S., A. Boettcher, N. Ueda \& C. Hohn. 2005. A simple transport procedure for juvenile calico scallops, Argopecten gibbus. J. Shellfish Res. 24:377-380.

Shi, H., W. Zheng, X. Zhang, M. Zhu \& D. Ding. 2013. Ecologicaleconomic assessment of monoculture and integrated multi-trophic aquaculture in Sanggou Bay of China. Aquaculture 410-411:172178.

Shumway, S. E. \& G. J. Parsons. 2016. Scallops: biology, ecology, aquaculture and fisheries, $3^{\text {rd }}$ edition. New York, NY: Elsevier. 1196 pp.

Sievers, M., I. Fitridge, T. Dempster \& M. J. Keough. 2013. Biofouling leads to reduced shell growth and flesh weight in the cultured mussel Mytilus galloprovincialis. Biofouling 29:97-107.

Smayda, T. J. 1997. Harmful algal blooms: their ecophysiology and general relevance to phytoplankton blooms in the sea. Limnol. Oceanogr. 42:1137-1153.

Stirling, H. P. \& B. Okumus. 1995. Growth and production of mussels (Mytilus edulis L.) suspended at salmon cages and shellfish farms in two Scottish sea lochs. Aquaculture 134:193-210.

Tan, Y., L. Huang, Q. Chen \& X. Huang. 2004. Seasonal variation in zooplankton composition and grazing impact on phytoplankton standing stock in the Pearl River Estuary, China. Cont. Shelf Res. 24:1949-1968.

Taylor, M. H., V. Koch, M. Wolff \& F. Sínsel. 2006. Evaluation of different shallow water culture methods for the scallop Nodipecten subnodosus using biologic and economic modeling. Aquaculture 254:301-316.

Wartenberg, R., L. Feng, J. J. Wu, Y. L. Mak, L. L. Chan, T. C. Telfer \& P. K. S. Lam. 2017. The impacts of suspended mariculture on coastal zones in China and the scope for integrated multi-trophic aquaculture (IMTA). Ecosyst. Health Sustain. 3:1340268.

Watson, D. I., S. E. Shumway \& R. B. Whitlatch. 2009. Biofouling and the shellfish industry. In: Shumway, S. E. \& G. Rodrick, editors. Shellfish safety and quality. Cambridge, MA: Woodhead Publishing. pp. 317-337.

Wong, W. H. \& S. G. Cheung. 1999. Feeding behaviour of the green mussel, Perna viridis (L.): responses to variation in seston quantity and quality. J. Exp. Mar. Biol. Ecol. 236:191-207.

Wong, W. H. \& S. G. Cheung. 2001. Feeding rates and scope for growth of green mussels, Perna viridis (L.) and their relationship with food availability in Kat O, Hong Kong. Aquaculture 193:123-137.

Wu, M., S. K. K. Mak, X. Zhang \& P. Y. Qian. 2003. The effect of cocultivation on the pearl yield of Pinctada martensi (Dumker). Aquaculture 221:347-356.

Xiao, J., S. E. Ford, H. Yang, G. Zhang, F. Zhang \& X. Guo. 2005. Studies on mass summer mortality of cultured zhikong scallops (Chlamys farreri Jones et Preston) in China. Aquaculture 250:602615.

Yang, H., T. Zhang, J. Wang, P. Wang, Y. He \& F. Zhang. 1999. Growth characteristics of Chlamys farreri and its relation with environmental factors in intensive raft-culture areas of Sishiliwan Bay, Yantai. J. Shellfish Res. 18:71-76.

Yin, K. 2002. Monsoonal influence on seasonal variations in nutrients and phytoplankton biomass in coastal waters of Hong Kong in the vicinity of the Pearl River estuary. Mar. Ecol. Prog. Ser. 245:111122.

Yu, Z., C. Hu, Y. Zhou, H. Li \& P. Peng. 2013. Survival and growth of the sea cucumber Holothuria leucospilota Brandt: a comparison between suspended and bottom cultures in a subtropical fish farm during summer. Aquacult. Res. 44:114-124.

Yu, Z., S. M. C. Robinson, J. Xia, H. Sun \& C. Hu. 2016. Growth, bioaccumulation and fodder potentials of the seaweed Sargassum hemiphyllum grown in oyster and fish farms of South China. Aquaculture 464:459-468.

Yu, Z., H. Yang, B. Liu, Q. Xu, K. Xing \& L. Zhang. 2010. Growth, survival and immune activity of scallops, Chlamys farreri Jones et 
Preston, compared between suspended and bottom culture in Haizhou Bay, China. Aquacult. Res. 41:814-827.

Yu, Z., Y. Zhou, H. Yang \& C. Hu. 2014a. Bottom culture of the sea cucumber Apostichopus japonicus Selenka (Echinodermata: Holothuroidea) in a fish farm, southern China. Aquacult. Res. 45:1434-1441.

Yu, Z., X. Zhu, Y. Jiang, P. Luo \& C. Hu. 2014b. Bioremediation and fodder potentials of two Sargassum spp. in coastal waters of Shenzhen, South China. Mar. Pollut. Bull. 85:797-802.

Zhang, F. S. \& H. S. Yang. 1999. Analysis of the cause of mass mortality of farming Chlamys farreri in summer in coastal areas of Shandong, China. Mar. Sci. (China) 1:44-47.
Zhang, Q. Z., Z. G. Liu \& H. Wang. 2008. Study on adaptability of juveniles of Chlamys nobilis to salinity. J. Guangdong Ocean Univ. $1: 1-10$.

Zhou, W., K. Yin, P. J. Harrison \& J. H. W. Lee. 2012. The influence of late summer typhoons and high river discharge on water quality in Hong Kong waters. Estuar. Coast. Shelf Sci. 111:35-47.

Zhou, Y., H. Yang, T. Zhang, P. Qin, X. Xu \& F. Zhang. 2006. Densitydependent effects on seston dynamics and rates of filtering and biodeposition of the suspension-cultured scallop Chlamys farreri in a eutrophic bay (northern China): an experimental study in semi-in situ flow-through systems. J. Mar. Syst. 59:143-158. 